Medical Physics | Review

\section{Aether, Fields \& Energy Dynamics in Living Bodies - Part III}

\author{
K. E. Thorp ${ }^{1}$, James A. Thorp ${ }^{2 *}$, Paul R. Walker ${ }^{3}$
}

'Department of Radiology, Sparrow Health System, Lansing, MI 2Department of Obstetrics and Gynecology, Division of Maternal Fetal Medicine, Sisters of St. Mary's Health System, St. Louis, MO.

${ }^{3} \mathrm{BSME}, \mathrm{MSEE}$
Submitted: 22 November 2021
Approved: 29 November 2021
Published: 30 November 2021

Address for correspondence:

James A. Thorp, Department of Obstetrics and Gynecology, Division of Maternal Fetal Medicine, Sisters of St. Mary's Health System, St. Louis, MO

How to cite this article: Thorp KE, Thorp JA, Walker PR. Aether, fields \& energy dynamics in living bodies - Part III. G Med Sci. 2021; 2(6): 021-047.

https://www.doi.org/10.46766/thegms.medphys.21112203

Copyright: @ 2021 K. E. Thorp, James A. Thorp, Paul R. Walker. This is an Open Access article distributed under the Creative Commons Attribution License, which permits unrestricted use, distribution, and reproduction in any medium, provided the original work is properly cited.

\section{Introduction}

Fundamental to the aether concept is seamless unity, a dynamic continuum of cause and effect, mediated by the opposing conjoined force fields that form the basis of action-at-a-distance and simultaneity. All action and reaction, from the macrocosmic level downward into the subatomic domain, is mediated through interactions between the aether-derived forces of magnetism and dielectricity which, in the end, give rise to space and matter. Equally, living bodies develop and thrive through the agency of such primordial forces. All bodily functions without exception represent the expression of conjoined field effects.

By the same token all disease, meaning the pathologic functional alterations and attendant symptoms, can be regarded as primary energy-deficient states in which imbalances originating between the magnetic, dielectric and their induced electric phenomena, produce altered states of function which, consequently, become expressed as disturbed nests of relations between various organs.

In the first installment of this paper, we examined the development of the aether concept from Aristotle through Wheeler and, in the second, showed how the aether field, through the aegis of magnetism, dielectricity, and derived electric currents, explains the entire gamut of energy dynamics in living bodies. In this third and final section we build on such principles and show how altered energetics play into the origin of various acute and chronic disease states which, for the most part, have resisted satisfying explanation on a cellular and molecular basis.

In order of presentation, we examine the dynamic origins of migraine headache, the poorly understood clinical entities posterior reversible encephalopathy syndrome, idiopathic intracranial hypertension, intra-abdominal hypertension, the cardiorenal syndrome, seizure disorder, and the inflammatory disorders. The examples we chose are not all-inclusive and their treatment, by necessity, is cursory and intended only to highlight their dynamic basis. More thorough and extended treatments of these entities are forthcoming.

\section{Migraines and the Magnetic Field}

Migraine headache, a chronic disabling condition with a female predominance of about 3:1, affects up to $15 \%$ of the world's population and is said to be the most common disabling disorder in people under fifty years of age. Nearly a billion people experience its effects annually. Its prevalence is said to be increasing [1].

The syndrome consists of four interconnected aspects: first, the premonitory phase, which may precede the headache by 48-72 hours, consists of symptoms like fatigue, irritability, mood change, impaired concentration, yawning, sensitivity to sound or light, and food cravings. Either shortly before or during the headache about onethird of subjects develop transient neurologic deficits, the so-called migraine aura, that may involve sensation, motor function, speech, or vision and which may persist for hours. The headache, which may last for hours up to 
several days, possesses a pulsatile quality and is often described as crushing or explosive. It may be accompanied by nausea, hypersensitivity to light and sounds, and is aggravated by physical activity. The postdromal phase, often mirroring the premonitory, may consist of fatigue, difficulty concentrating and neck stiffness [2].

In the late $19^{\text {th }}$ century British physician Peter Latham argued that migraines were a result of arterial dilation $[3,4]$. This notion was reinforced following the introduction of nitroglycerine (NTG) around the turn of the $20^{\text {th }}$ century for treatment of angina pectoris in coronary artery disease. Following relief of chest pain individuals not uncommonly experienced explosive migraine-type headaches. Over the decades this association was strengthened by the recognition that nitrate compounds often triggered headaches in migraineurs [5-10]. In the 1940s studies showed that headache-like pain and nausea could be generated by stimulation of the dura mater, particularly in proximity to dural and cerebral blood vessels [11].
It is now known that vasodilation per se does not cause headache and that neural factors mediate the pain. Dural blood vessels are richly innervated by pain-sensitive axons that originate in trigeminal ganglia and it is activation of these sensory fibers that triggers migraine headache. The pulsatility of the headache, moreover, is not synchronous with cardiac pulsations. Migraine syndrome is now regarded as a neurovascular disorder but its origins remain obscure.

All the nervous system manifestations of migraine can be explained on the basis of two primary functional disturbances, desynchronization between the vascular and nervous compartments and hyperexcitability of sensory neurons. These phenomena, in turn, originate from destabilization of the magnetic field which itself can be traced to a primary liver dysfunction which, as noted in part II of this series, corresponds to the heart-liver-brain axis of the biologically closed electric circuit (Figure 1).

\section{Figure 1. Image of the heart-liver-brain axis.}

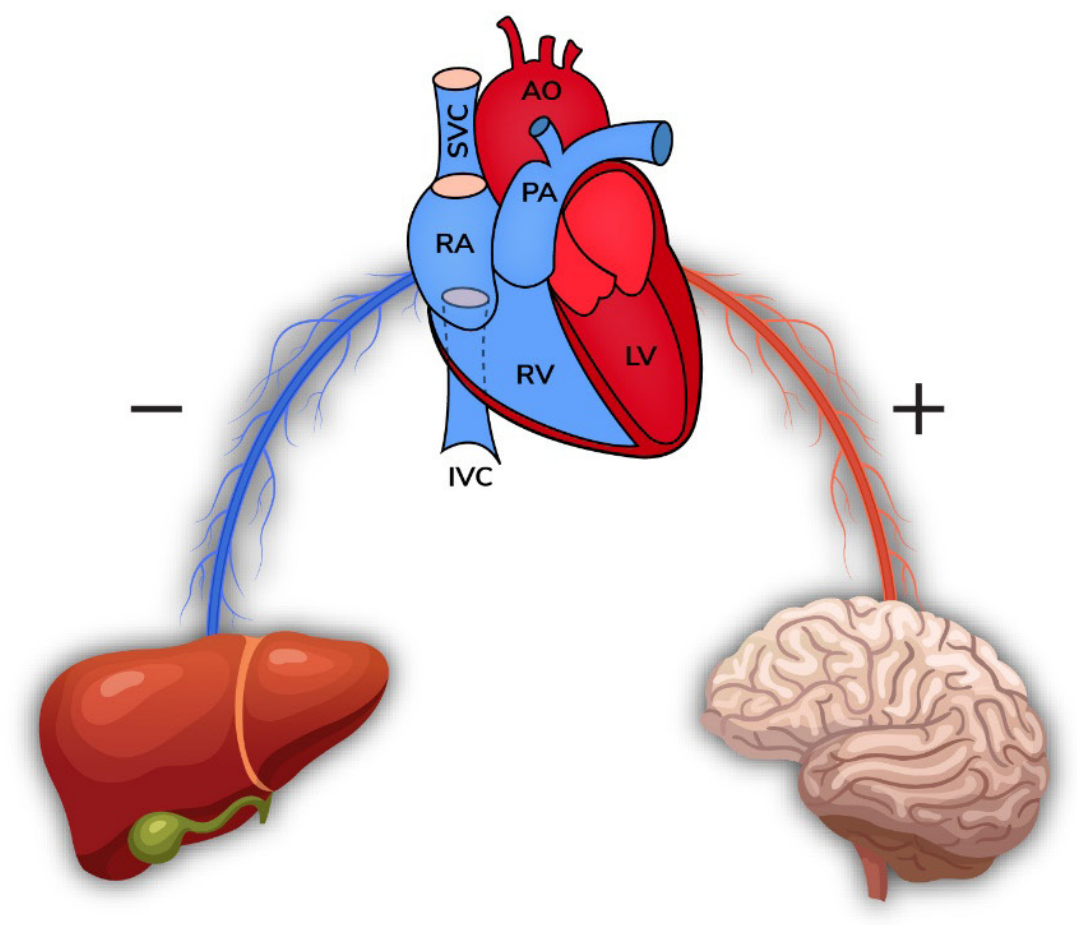

Figure 1: Altered dielectric-magnetic field dynamics between liver, brain and heart drive all symptoms and associated functional disturbances in migraine headache syndrome. 
Typically, visual auras begin prior to the headache as a blind spot or shimmering focus near the center of the optical field. In the 1940 s Leão electrically stimulated the cerebral cortex in rabbits and generated a wave of depressed EEG activity that spread centrifugally in all directions over the brain surface at about $3 \mathrm{~mm} / \mathrm{min}$. He subsequently deduced that the migraineurs visual aura was a result of such 'cortical spreading depression' (CSD) [12-17].

CSD, a slowly propagating wave of neuronal depolarization followed by a period of suppressed activity, is a common accompaniment of various forms of brain injury such as stroke, trauma, or intracranial hemorrhage. Common to all these states is an uncoupling of neural and vascular mechanisms. At the neuronal level this manifests in impaired dielectric capacitance with disruption of ioninduced current flow, profound shifts in ionic balance between the intra- and extracellular water compartments, and inability to elicit aether flux [18-26].

This desynchronization manifests as dramatic alterations in blood flow throughout the cerebrum with waves of hyperemia followed by periods of hypoperfusion. Disturbances in regional blood flow occur with some areas being hyperemic and others oligemic. Regional hypoperfusion may give rise to transient ischemic events involving speech or motor centers as well. Such aurarelated imbalances may persist for an hour or more.

In non-migraineurs individuals neural and vascular activities are tightly coupled with a highly regulated interplay between the two systems to maintain regional blood flow, energy generation, and delivery of metabolic substances [27-29]. In migraineurs the state of neurovascular desynchronization fails to return to normal following the migraine attack leading to a chronic state of cortical susceptibility not dissimilar to that seen in seizure disorder. This condition may be exacerbated by the very medications' subjects use to ameliorate the headache pain [30-32].

The areas of regional hyperemia seen by various imaging modalities in migraine are generated by vasodilation not in arteries proper, as earlier researchers argued, but, instead, at the arteriolar and capillary levels and, rather than being the cause of the syndrome, are a result of desynchronization between the neural and vascular compartments. And the tendency of nitric oxide donors such as NTG or various neuromodulators like the prostaglandins or calcitonin related gene peptide (CGRP) to produce migraine-like headache symptoms occurs not on the basis of vasodilation itself but by inducing further desynchronization between the two compartments [3342].

Beginning in the mid-1990s regional blood flow studies generated new insights into the altered excitability of sensory neurons, known as allodynia, in migraineurs. Individuals with allodynia experience pain related to various external stimuli that others experience as normal sensation. Many migraineurs develop allodynia during migraines, and many remain hypersensitive between attacks. In addition to regional flow disturbances in the hemispheres, researchers found increased flow in the brainstem suggesting it was involved in migraine pathogenesis.

Attention soon focused on an area in the midbrain called the periaqueductal gray (PAG) which plays a key role in modulating pain responses as well autonomic balance. Studies found that migraineurs with allodynia had atypical resting-state connectivity patterns between the PAG and regions in the brainstem, thalamus insula, and cortex known to be involved in processing and modulation of pain. Evidence points toward a dysfunctional dynamic in which pain pathways are in a chronic state of excitation and inhibitory circuits unable to suppress the altered state of excitability. As the frequency of headache increases, the strength of connectivity between the PAG and the pain processing network increases [43-51]. How to explain such phenomena? Evidence began to point to the bloodborne magnetic field.

MRI studies found abnormal iron homeostasis in the PAG of migraineurs which was tied into neuronal dysfunction. Significant increase in tissue iron levels is found in episodic and chronic migraine subjects when compared to controls. As the frequency of migraine attacks increases so too do iron levels suggesting a relation to repeated attacks [52-56]. Individuals with hemochromatosis, a hereditary disorder of iron metabolism, have a higher incidence of headache [57-58]. The liver is the seat of iron metabolism in the body and such findings point an incriminating finger in its direction [59-61]. The evidence becomes even more compelling once one reexamines the premonitory phase with a more critical eye.

What is the basis for symptoms like fatigue, depression, impaired concentration, yawning or food cravings that precede the headache? Such constitutional symptoms have been attributed to 'hypothalamic dysfunction' resulting in neural 'loss of control' which is said to trigger the subsequent aura and headache [62-66]. This ridiculous notion, which forms the cornerstone of neurophysiology, was advanced in the early $20^{\text {th }}$ century by English researcher Charles Sherrington who claimed that the 'dominant brain' controlled all bodily processes [67]. But the fact that such symptoms register as voltage potentials in the hypothalamus in no way suggests that the hypothalamus causes them.

In reality, such premonitory phenomena originate in the blood and signal an energy deficient state. How 
else is one to explain fatigue or food cravings? [68]. Studies from the Middle East indicate that fasting during Ramadan is associated with increased incidence of migraine events [69-71]. Other studies find that physical exertion, including sexual activity, not uncommonly trigger migraines [72-75]. How can such associations be explained without invoking energy availability?

In recent decades the notion of the gut-brain axis, connoting a bidirectional nexus of relationship between the brain and the digestive system, has come into vogue. It is generally overlooked that these functional relations are mediated through the liver and blood. Migraine is often associated with GI disturbances like diarrhea, constipation, dyspepsia, gastroesophageal reflux as well as disorders like $\mathrm{H}$. pylori colonization, gut dysbiosis, irritable bowel syndrome, celiac disease, and inflammatory bowel disease. It is likely that impaired absorption dynamics and gut wall inflammation introduce substances into the portal venous system that affect liver function. By the same token alcohol ingestion, a very common migraine trigger, induces transient hepatic stress.

Chinese medicine is the oldest dynamic energy-based system on the planet. Central to it is the notion of Qi, which is aether, and its two primary offspring Yin, the dielectric, and Yang, the magnetic. Not coincidentally, in Chinese medicine migraine headaches are said to be liver-induced and correspond to an imbalance pattern known as liveryang rising, a result of liver-yin (dielectric) deficiency and liver-yang (magnetic) excess with resultant rising of liver-yang into the head. Such headaches, like migraines, are typically one-sided and along the lateral side of the head. The primary function of the liver is to maintain

Figure 2. Video clip of CT scans. balance and a smooth flow of liver-qi throughout the body [99].

\section{Impaired Venous Return}

The next group of disorders begin as an acute or chronic deficiency of radiant energy in the interstitial fluid space that ultimately compromises renal function. As a consequence, the kidneys, through the renin-angiotensin system and adrenal axis, attempt to increase short-term energy generation by the heart so as to draw more energy from the blood. Effects upon the vascular system include elevated heart rate and blood pressure which, ultimately, lead to prolongation of the systolic (dielectric) phase of the cardiac cycle at the expense of the diastolic (magnetic). In susceptible individuals this expresses itself as impaired diastolic function, i.e., insufficient suction pressure, of the right ventricle resulting in diminished venous return in various body compartments.

The dynamics of venous return remain one of the least understood areas of medical physiology. When William Harvey denied active dilation and proclaimed diastole to be a period of relaxation, he excluded any possible means by which fluid in the interstitial compartment could return to the heart. In a 1971 essay, On the Motion of Blood, Lord Cohen of Birkenhead attempted to unravel the mystery of venous return [100]. In the centuries since Harvey's publication of On the Motions of the Heart, Cohen observed, there had been extensive scientific debate concerning the forgotten part of the circulation but no explanation for how blood returns to the right heart ever emerged. The rediscovery of active ventricular dilation in the $1980 \mathrm{~s}$ resolves this conundrum (Figure 2).

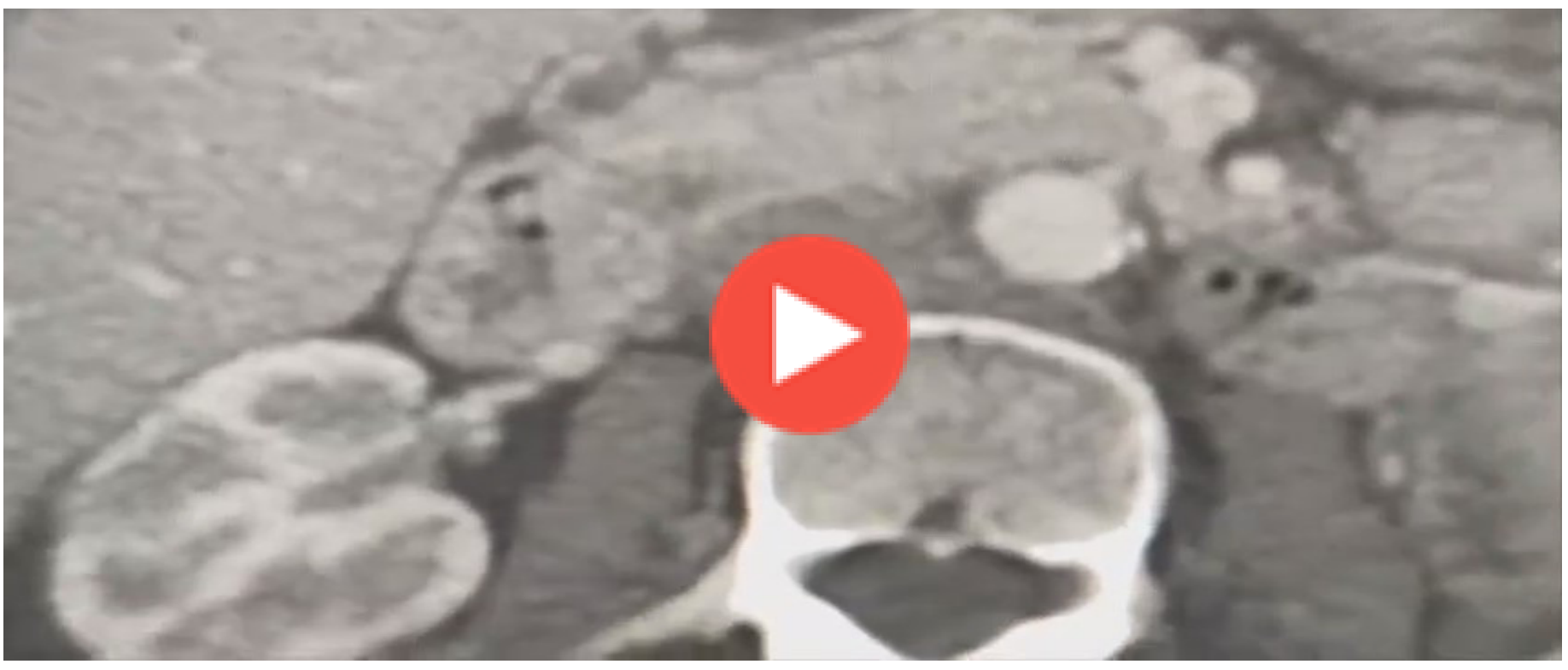

Figure 2: Axial CT images through the upper abdomen demonstrate counterclockwise spiral flow currents of intravascular contrast material as it passes from the renal veins into the non-opacified inferior vena cava (grey circular structure) and upward toward the right ventricle. 
Posterior reversible encephalopathy syndrome (PRES), first described in 1996, is associated with headache, confusion, focal neurologic deficits which may progress to seizures, coma and occasionally death. Seen in both adults and children, it presents most commonly as edema in the posterior white matter regions although other patterns of involvement occur (Figure 3). It has been attributed to impaired regulation of cerebral blood flow and resultant imbalance between arterial constriction and dilation. Such explanations don't even consider the possibility of altered venous dynamics [58-60].

\section{Figure 3. Axial T2-weighted MRI image of brain}

PRES has been described in association with hypertensive crises, the preeclampsia-eclampsia syndrome, vascular and autoimmune disorders, various renal conditions including chronic kidney disease, as well as immunosuppressive and antineoplastic drugs. It is also associated with various cardiac disorders including Takotsubo cardiomyopathy or 'broken-heart syndrome,' which presents as ventricular dysfunction associated with emotional disturbances like stress and

bereavement. PRES is a common sequela of cardiac transplantation. Treatment for PRES is largely supportive [101-112].

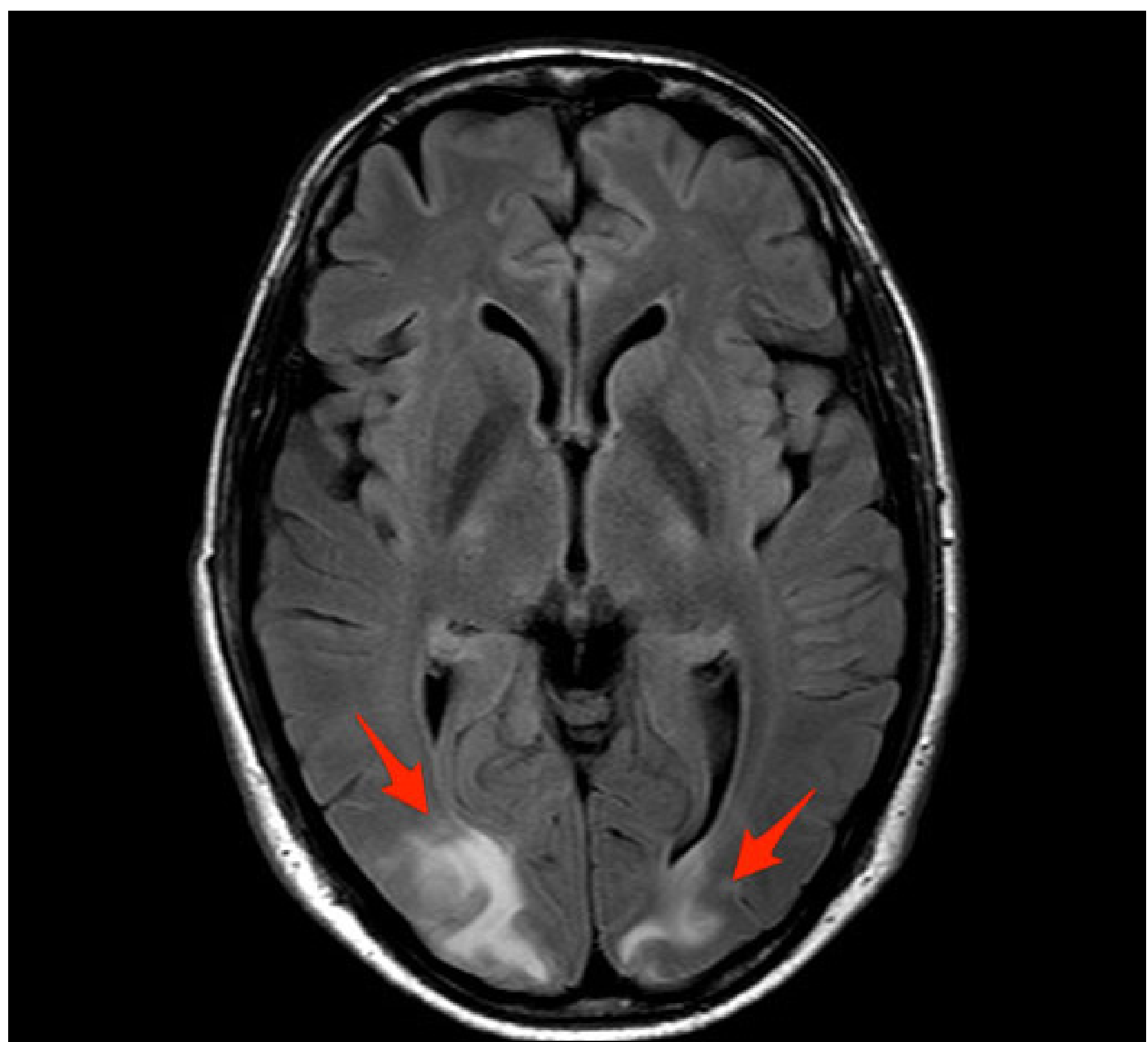

[Case courtesy of Dr Hani Makky Al Salam, Radiopaedia.org, rID: 7697]

Figure 3: Posterior reversible encephalopathy syndrome (PRES) on axial T2-weighted MR image shows increased water signal in white matter tracts of both occipital regions (red arrow) secondary to right ventricular diastolic dysfunction induced by primary energy deficiency in the kidneys. 
Another venous-mediated disorder having similar origins is idiopathic intracranial hypertension (IIH), a syndrome that most frequently affects young obese women but also occurs sporadically in other demographic groups. Symptoms, which may include disabling headache, visual disturbances, pulsatile tinnitus, and neck pain, are secondary to elevated intracranial pressure. Its cause is unknown. Ocular findings include papilledema often associated with sixth cranial nerve palsy (Figure 4). On lumbar puncture opening pressures are elevated and may reach up into $75-80 \mathrm{~cm}_{2} \mathrm{O}$ range with normal cerebrospinal fluid (CSF) composition. IIH rates have risen in recent decades in parallel with obesity [113-117].

Figure 4. Sagittal MRI image of brain with red arrows on the sella turcica.

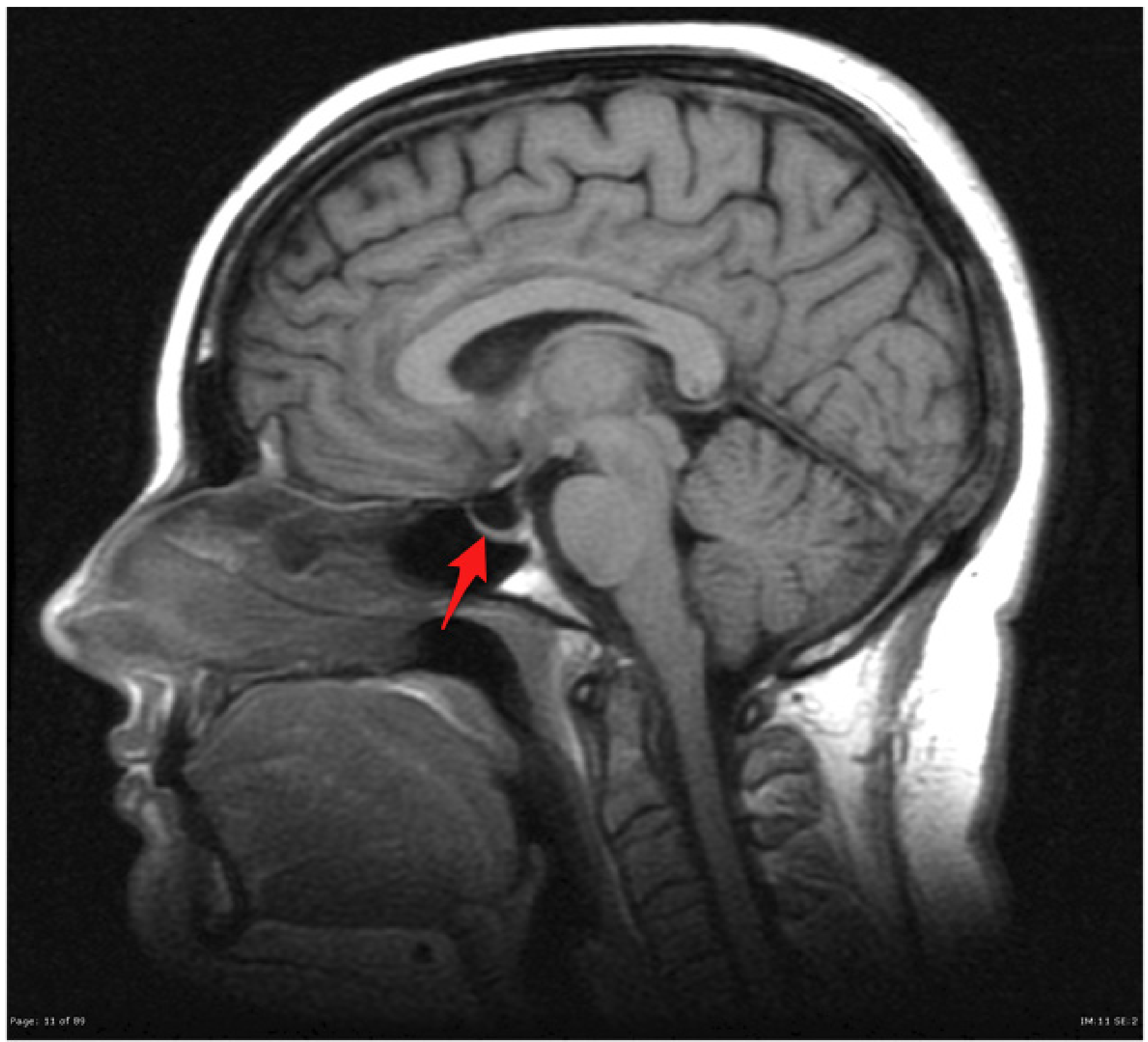

[Case courtesy of Assoc Prof Frank Gaillard, Radiopaedia.org, rID: 17839]

Figure 4: Sagittal T1-weighted MR image of idiopathic intracranial hypertension (pseudotumor cerebri) producing so-called empty sella syndrome. Dilated outpouching of subarachnoid fluid space into the sella turcica (red arrow) produces pancake deformation of the pituitary. 
The CSF circulation has been a recurrent topic of debate since first described in the $18^{\text {th }}$ century. CSF is produced from the blood by the choroid plexus in the lateral ventricles. At any given time, there is about $150 \mathrm{cc}$ circulating through the ventricles and subarachnoid space. By unknown mechanisms it is drawn upward over the convexity of the hemispheres and reabsorbed through the arachnoid granulations into the sagittal sinus. The only mechanism by which CSF circulation and reabsorption could occur is a diastolic suctional force generated by the right ventricle [118-123].

The connection between PRES, IIH and the kidneys is seen in the preeclampsia-eclampsia syndrome, a leading cause of maternal and fetal morbidity worldwide, which also takes origin in the venous side of the circulation. Preeclampsia, a multicompartmental disorder affecting about $5 \%$ of all pregnancies, is heralded by maternal hypertension and proteinuria usually after the $20^{\text {th }}$ week of gestation. Symptoms may include headache, visual disturbances, confusion, seizures and hypertensive brain hemorrhage. PRES and IIH are known accompaniments. Eclampsia denotes the onset of late-term or postpartum seizures. Risk factors include hypertension, diabetes, obesity and a family history of heart disease [69-71].

Maternal hypertension and proteinuria indicate functional decompensation of the kidneys with activation of the renin-angiotensin in an attempt to import additional blood-borne energy into the renal axis. This, in turn, induces diastolic dysfunction with elevated central venous pressure (CVP) which only compounds the problem. In addition to sequelae like PRES and IIH, elevated proinflammatory cytokines are found which has led some to incriminate the immune system in the etiology of preeclampsia. The maternal risk factor profile implicates a preexisting energy defect in the mother that is aggravated by the gestational state [124-127]. Studies find abnormal vascularization of the placenta which has been ascribed to hypoxia $[128,129]$. To counteract this the fetal placenta secretes large amounts of vascular endothelial growth factor (VEGF) to stimulate angiogenesis; this is actively opposed by various anti-VEGF factors released on the maternal side that block angiogenesis. This oppositional dynamic reflects insufficient energy flow across the placenta from the mother to the fetus.

The effects of right-sided diastolic dysfunction involve more than the CNS. In 2005 a study followed 265 patients admitted to the ICU for various reasons [130]. Intra-abdominal pressures (IAP) were measured in all subjects via an indwelling urinary bladder catheter. Intra-abdominal hypertension, i.e., IAP greater than 12 $\mathrm{mmHg}$, was associated with severe organ failure and higher mortality. A 2009 study found that patients with acute heart failure (HF) have a high prevalence of elevated IAP despite an absence of abdominal complaints [131].
Pressure-related phenomena include ascites, congestive liver dysfunction, and bowel wall edema. The trail leads back to the kidneys.

The $20^{\text {th }}$ century model of renal failure attributed impaired kidney function to diminished arterial inflow which, in turn, activated the renin-angiotensin system and adrenal axis so as to increase cardiac output and renal blood flow, leading to hypertension, and caused the kidneys to retain sodium and water leading to volume overload and peripheral edema. A 2008 study examining factors associated with worsening renal function in acute HF patients, concluded that the arterial flow model did not explain the functional deterioration. The strongest determinant was, instead, elevated right atrial pressure, i.e., diastolic dysfunction [132]. A 2009 study of 145 patients with acute HF found that venous congestion is the most significant hemodynamic factor precipitating worsening renal function [133].

Elevated CVP is now recognized to be the primary driver of deteriorating renal function. Transmission of elevated CVP into the kidneys raises intrarenal pressure which secondarily decreases arterial inflow. It's not that the kidneys reabsorb more sodium and water; rather, due to increased back-pressure, the normal arterial-venous pressure gradient is diminished so that less urine and sodium are filtered. This mechanism also explains proteinuria. By the same token impaired diastolic function of the right ventricle results in accumulation of fluid in the lower extremities causing peripheral edema. These downstream pathologic sequelae are mediated by real physical forces that can only be explained on the basis of deterioration of the magnetic field.

The relation between increased venous pressure and decreased renal function was recognized well over a century ago but was never incorporated into the medical framework. In 1861 German physiologist Ludwig observed in lab animals that as renal vein pressures increased urine flow decreased. In 1931 Winton described a 'steeply graded' relation between renal venous pressure and urine flow [134]. Arterial inflow was less a factor than raised venous pressure. In the 1980 s studies found that transient compression of the renal veins decreased the filtration rate of urine along with sodium excretion [135-137]. Not only was the $20^{\text {th }}$ century systolic-based cardiac model of blood flow incapable of explaining such findings it actually prevented researchers from interpreting results correctly.

In 2008 a new clinical entity was described, the cardiorenal syndrome, which points to an intertwined nexus of deterioration in the heart-kidney axis. Patients with cardiac disorders not infrequently develop renal deterioration. Patients with kidney disease often develop cardiac dysfunction. Such bidirectional cause-and-effect reflects the tightly linked energy field shared by the two 
organs. Medical researchers are unable to explain this complex action-at-a-distance interplay. They describe a host of cellular, molecular and neural aberrations which are supposedly a result of a 'cascade of feedback mechanisms'. Inflammation is thought to play a key modulating role. But none of these descriptions amount to an explanation [138-144].

The burgeoning cardiorenal syndrome is associated with significant morbidity and mortality. As the venousmediated deterioration of renal function advances, the renin-angiotensin and sympathetic systems overcompensate and set into motion a vicious spiral of deterioration. The result is worsening arterial constriction, more ventricular wall stiffness and thickening, rising blood pressure, increasing inflammation, with further impairment of diastolic function and energy generation. Alongside this CVP continues to rise leading to worsening kidney function. And to compound matters, therapies intended to improve HF worsen renal function and those intended to enhance renal function adversely impact the heart. In the face of diminishing energy generation all currently employed treatments simply rob Peter to pay Paul.

\section{Seizure and Aether Dynamics}

For centuries the mysterious affliction called epilepsy has fascinated physicians and philosophers. Epilepsy is a common neurological disorder with a worldwide prevalence of about $1.0 \%$, which translates globally to about 60-80 million affected individuals. About $10 \%$ of the general public will experience at least one seizure during their lifetimes and approximately one-third of these will develop epilepsy [145]. A seizure is a transient appearance of involuntary sensation and/or movement resulting from excessive, synchronous neuronal discharge in the brain. Epilepsy is the underlying condition that predisposes to seizure activity $[146,147]$.

There are about thirty anti-epileptic drugs available for the treatment of epilepsy [148]. Despite this up to $35 \%$ of individuals with epilepsy fail to attain seizure-free status with treatment [149]. While these drugs reduce the frequency of seizure events none alter the course of the underlying epileptic state and all are associated with a range of insalubrious side effects.

By the late $19^{\text {th }}$ century, it was known that when areas of the cerebral cortex were electrically stimulated focal seizures were generated that depended on the strength and location of the electrode. Neurologist John Hughlings Jackson argued that seizures result from excessive neuronal discharges within a particular brain area which then spreads into adjacent regions as the seizure evolves. As the location of the discharge focus varies seizure manifestations vary. But while the anatomical locus may change the underlying disturbance is always the same. The seizure focus, he wrote, was 'over-unstable,' i.e., hyper-excitable, and prone to release its energy more readily than normal cells [150].

In the 1930s neurosurgeon Wilder Penfield studied the functional anatomy in epilepsy patients using electrical stimulation during surgery and found that sensory, motor, or affective symptoms as well as seizures could be elicited by stimulation of discrete areas of cortex. Surgical removal of the abnormal area of cortex often brought relief from the seizures.

In an illuminating 1960 piece entitled 'All Epilepsy is One,' neurologist Roland Mackay synthesized previous concepts into a unitary hypothesis [151]. The division of seizures into various types like generalized or focal, major or minor, sensory or motor, helps describe the characteristics of a given seizure but does nothing to explain the dynamics that trigger the event. Given that seizures can be induced by so many stimuli, convulsability must be regarded as a generalized property of nervous tissue.

From his series of cases Mackay concluded that there is no such thing as a pure seizure type. All seizures are variations on the same theme. There are two features that characterize seizure events: 'autorhythmicity' or hyperexcitability, which is related to loss of threshold potentials, and 'hypersynchrony,' the spontaneous firing of larger neuronal populations in the same rhythm and frequency, now known as recruitment.

In the 1940s, neurophysiologists observed that upon stimulation the electrical activity in cortical neurons became readily synchronized and deduced that the inphase discharges were a result of direct contact between adjacent cells. Such synchronization, called ephaptic coupling, is mediated by the side-to-side or horizontal spread of rhythmic activity to adjacent cell populations. Mackay was among the first to relate ephaptic coupling with neuronal recruitment and hypersynchrony [152].

In recent decades much attention has been paid to the circadian pattern of seizures. Numerous reports describe a daily periodicity of various seizure types but there is little agreement as to why seizures tend to occur at specific times of the day or night $[153,154]$. The fact that a given seizure type is prone to occur at one time or another does not imply that it has a different etiology than any other seizure. Nor is there any evidence to suggest that one seizure form should be treated differently than any another. Like Mackay we are drawn toward a single global mechanism at play behind all seizures which is loss of threshold potentials and hyperexcitability.

Magnetoencephalography (MEG) studies report increased cortical excitability in the $24-48 \mathrm{~h}$ period preceding 
seizure onset [155-159]. EEG studies found increased number of interictal epileptiform discharges (IEDs) in the preictal period, also suggesting heightened cortical excitability. Such hyper-responsiveness can be attributed to diminished amplitude of the wave function, i.e., threshold, between depolarization and repolarization. This is the universal physiologic basis of the epileptic state.

This explains the long-recognized relationship between sleep disturbances and seizure frequency [160, 161]. Studies suggest that up to $40 \%$ of adult epileptics have sleep disturbances. Loss of threshold also explains the well-recognized relation between stress and seizure frequency $[162,163]$. Stress, particularly emotional stress, is one of the most commonly reported seizure triggers independent of the type of epilepsy. Loss of amplitude also accounts for the relation between epilepsy and depression [164]. Depression is the most common psychiatric condition associated with epilepsy. The clustering of epilepsy, sleep, stress and depression suggests that far from being a disturbance of local neuronal populations, seizure disorder represents a global functional disturbance related to loss of threshold.

Seizures aren't random or haphazard in their occurrence. No matter how they may manifest, all seizures possess a beginning, a middle, and an end. The recognition of heightened cortical excitability in the hours to days preceding the epileptic attack indicates a premonitory phase. Some subjects describe vague changes in mood and affect during these periods. While studies have cast light on the epileptogenic milieu in the preictal phase, only in the last decade have researchers addressed another significant question: why do seizures suddenly terminate?

Another MEG study found marked reduction in cortical excitability persisting for up to $24 \mathrm{~h}$ post-ictal, suggesting a state of hyperpolarization $[165,166]$. Postictal EEG anomalies are often present and include polymorphic delta activity, alteration of baseline EEG rhythms or focal spikes. This electrophysiologic state can last for hours. Epileptic subjects often report postictal changes such as confusion and amnesia which, for some, make this period even more disturbing than the seizure itself.

The hyperpolarized milieu explains postictal generalized EEG suppression (PGES) and sudden unexplained death in epilepsy (SUDEP), two common phenomena associated with the postictal state for which medical science has no compelling explanation [167]. PGES, defined as postictal absence of normal EEG activity, has been described in subjects following generalized seizures. Beyond the EEG changes subjects experience immobility, respiratory depression, and alterations in consciousness [168]. SUDEP, the most common cause of death in epileptics, is also associated with generalized seizure [168, 169]. Both
PGES and SUDEP occur more often at night and during the sleep state. SUDEP has been linked to sudden, intense increases in geomagnetic activity related to sunspot activity.

Hyperpolarization is a functional state that can only be explained on the basis of an influx of energy currents into affected neural networks. Given that only moments earlier in the preictal period cell membranes were hyperirritable and prone to discharge their currents one is hard-pressed to attribute this striking change to energy generation by the already-malfunctioning cellular machinery. It is more likely that affected neuronal regions import energy into the CNS from elsewhere. The hyperpolarization phenomenon implicates a body-wide energetic milieu involving the cardiovascular system.

That the cardiovascular system plays a role in seizure termination is supported by numerous studies [170, 171]. A rash of cardiac rhythmic disturbances including ictal tachycardias and bradycardias, ictal and postictal asystole, ictal and postictal A-V conduction blocks, as well as postictal atrial and ventricular fibrillation were observed in one study [172]. Authors speculated that such disturbances were tied into the genesis of SUDEP. Another study described frequent potentially high-risk cardiac arrhythmias following generalized seizure events [173].

Yet another study found persistent ECG changes and body-wide autonomic imbalances in the postictal phase that directly correlated with the presence of PGES [174]. Autonomic activity after generalized seizures was profoundly affected and lasted for 1-2 hours. During this period of prolonged sympathetic outpouring there was suppression of vagal activity which persisted even after sympathetic activity returned to baseline. Studies consistently link decreased vagal activity with heightened risk for sudden cardiac death. Such results unequivocally tie energy flow in the CNS and seizure termination into a commonly shared energy field that has its origins in the cardiovascular system.

In 1997 a children's show in Japan aired a cartoon sequence depicting a rocket launch with rapidly oscillating red and blue colors that induced a variety of seizure types in 500-600 school-age children. About three-fourths of the children had no previous history of seizures [175]. Photic-induced seizures are produced by visual events, usually flashing light, but also complex patterns like checkerboards, fencing and gridlines. We must assume that the mechanisms underlying visuallyprovoked seizures are identical to the dynamics we have just reviewed.

Even more common than photic-induced seizures are photosensitivity in which individuals provoked by light stimuli develop abnormal EEG responses [176]. Seizure 
induction is most common with light flash frequencies in the $15-25 \mathrm{~Hz}$ range. Individuals with normal neuronal thresholds, when subjected to a pulsed light train, exhibit synchronous phase-locked EEG activity, known as a visual-evoked response, in the occipital region which does not extend beyond the population of activated sensory neurons. Light-sensitive individuals, on the other hand, develop what is called a photoparoxysmal response (PPR), IED-like patterns, mostly spike-waves and intermittent slow waves, that spread by recruitment into other brain territories.

Such events are mediated by electromagnetic fields. Using MEG to study brain dynamics associated with intermittent photic stimulation, two studies observed phase-clustering in the gamma band $(30-120 \mathrm{~Hz})$ directly related to the primary frequency of stimulation $[177,178]$. In subjects who developed a PPR there was enhancement of phase synchrony related to neuronal recruitment. Findings highlight the primary role the radiant energy field plays in the functioning of neuronal networks.

The recognition that light, when administered at particular frequencies, is capable of inducing neuronal instability or frank seizures in susceptible individuals raised the question as to whether, when applied under different conditions and frequencies, it is capable of stabilizing membranes and diminishing or preventing seizure occurrence [179-181]. Several years ago, one of the authors (PW) developed a light system consisting of two banks of computer-controlled low frequency/low power and high frequency/high power LED lights driven by a programmed sequence that resonates water in a manner not unlike a pulsed MRI field.

Our first opportunity to test the device was in a 61-year-old woman with chronic seizure secondary to cerebral hemorrhage from a vascular malformation. She experienced 2-3 sensory seizures per day that were eventually controlled by Keppra but with disabling side effects. Light was delivered in pulsed 30-minute sequences twice a day to her face. Over four weeks we gradually withdrew her medication. She has remained seizure-free for over 2 years while receiving one light treatment per day. There have been no light-induced side effects.

Despite this remarkable outcome the predisposing cause, cellular damage at the site of previous injury, was apparently unaffected by therapy. When light was discontinued, she developed premonitory symptoms within 3-4 days signaling impending seizure and light treatment was promptly resumed. This suggests persistent dielectric field impairment with loss of capacitance and inability to induce aether flux. As we will see, this necessitates supplementation of light therapy with compounds to alter the dielectric milieu at the cellular level.

\section{Inflammation and the Dielectric Field}

First century AD Roman writer Celsus is credited with introducing the four cardinal signs of inflammation, tumor (swelling), rubor (redness), calor (heat), and dolor (pain), which have been used by physicians for centuries to assess the progression and extent of the inflammatory process. The reliability of the four signs as clinical indicators and prognosticators has been widely affirmed [182].

Functional events involved in the inflammatory response occur in an orderly sequence: the response is triggered in the interstitial fluid space through the release of cytokines by macrophages and neutrophils which induce constriction of venules thus impairing suction of fluid into veins by active dilation of the right ventricle. Other cytokines induce dilation of arterioles which increases flow into the affected area producing redness of the skin as well as throbbing and pain. Heat indicates increased cellular metabolism in the affected tissues. The inflammatory response is an attempt by immune cells to stimulate energy generation in energy-deficient tissues. Since the time of Galen, it was widely held among physicians that inflammation originated in the blood.

At the turn of the $20^{\text {th }}$ century inflammation was regarded as a defense mechanism related solely to infection but this notion was soon put to rest when it was shown to be involved in allergic reactions and, decades later, autoimmune disorders. By the end of the century inflammation had been found to be an invariant feature of a wide spectrum of conditions including asthma and chronic lung disease, acute and chronic kidney disease, chronic heart failure and atherosclerosis, acute stroke and neurodegenerative disorders like Alzheimer's and Parkinson's, type I and type II diabetes, as well as various cancers [183-203]. Runaway systemic inflammation associated with Covid-19 infection has been wellchronicled. Scientists still can't agree on the purpose of inflammation [204-206]. What is it about either the immune system or these various disease processes that invokes such a response?

This first line of evidence points to a fundamental misinterpretation of the immune system. For much of the $20^{\text {th }}$ century it was regarded as a defense system that protected the host against outside invaders and functioned through the synthesis and release of pathogen-specific antibodies. But this interpretation was not universally accepted. In the 1880 s Elie Metchnikoff introduced a rose thorn into a starfish larva and watched under the microscope as cells surrounded the foreign object. Calling them phagocytes or 'eating cells' Metchnikoff argued that white blood cells and macrophages were part of a more general set of functions, an internal digestive system, the purpose of which was to mediate the breakdown of molecular and cellular substances. 
The digestive system represents a set of organismic functions that orchestrate the orderly assimilation, breakdown and elimination of substances. The two primary digestive organs, the stomach and spleen, have conjoined origins in the left upper quadrant of the abdominal cavity and employ similar metabolic pathways centered around the generation and use of acid and acidactivated enzyme systems to mediate their catabolic activities.

The two organs constitute an integrated functional nexus: the stomach takes in food material from the outside which, upon decomposition, is drawn upward through intestinal veins to the liver where it is altered and then transported through arteries to the interstitial fluid space for use by cells; the splenic phase of the cycle, i.e., the internal digestive system proper, begins with the organized intracellular breakdown of molecules and organelles, called autophagy, and extrusion of waste into the interstitial fluid space, its uptake into veins, and return to the spleen for elimination or recycling.

The two main phagocytic cell lines, macrophages and polymorphonuclear neutrophils (PMNs) carry out digestive functions in the fluid spaces as Metchnikoff correctly surmised [207-209]. There is very little in terms of the immune response proper that distinguishes infection-related inflammation from any other variety. In all cases immune cells respond to what is called 'damage associated molecular patterns' (DAMPs) and carry out their digestive functions. Antibody synthesis is but a late accompaniment. As Mackay concluded regarding seizures, we are drawn toward the unitary nature of all inflammation.

The primary trigger for activation of all inflammatory pathways is disturbed intracellular energy flow between mitochondria, which orchestrate aerobic energy metabolism, and lysosomes, the site of intracellular digestion. This defect, in turn, is mediated by shift of cellular metabolism away from cathodically-driven, magnetic-dominant processes in the alkaline $\mathrm{pH}$ range that characterize aerobic energy generation, toward the anodic pole in which cytoplasm is acidic and under the influence of the dielectric field. Such a shift is necessitated by loss of capacitance and aether flux into affected cells. These field-indced behaviors correspond to the biologically closed electric circuits described by Nordenström (Figure 5).

Figure 5. Diagram of Dielectric Field dynamics in a water bath.

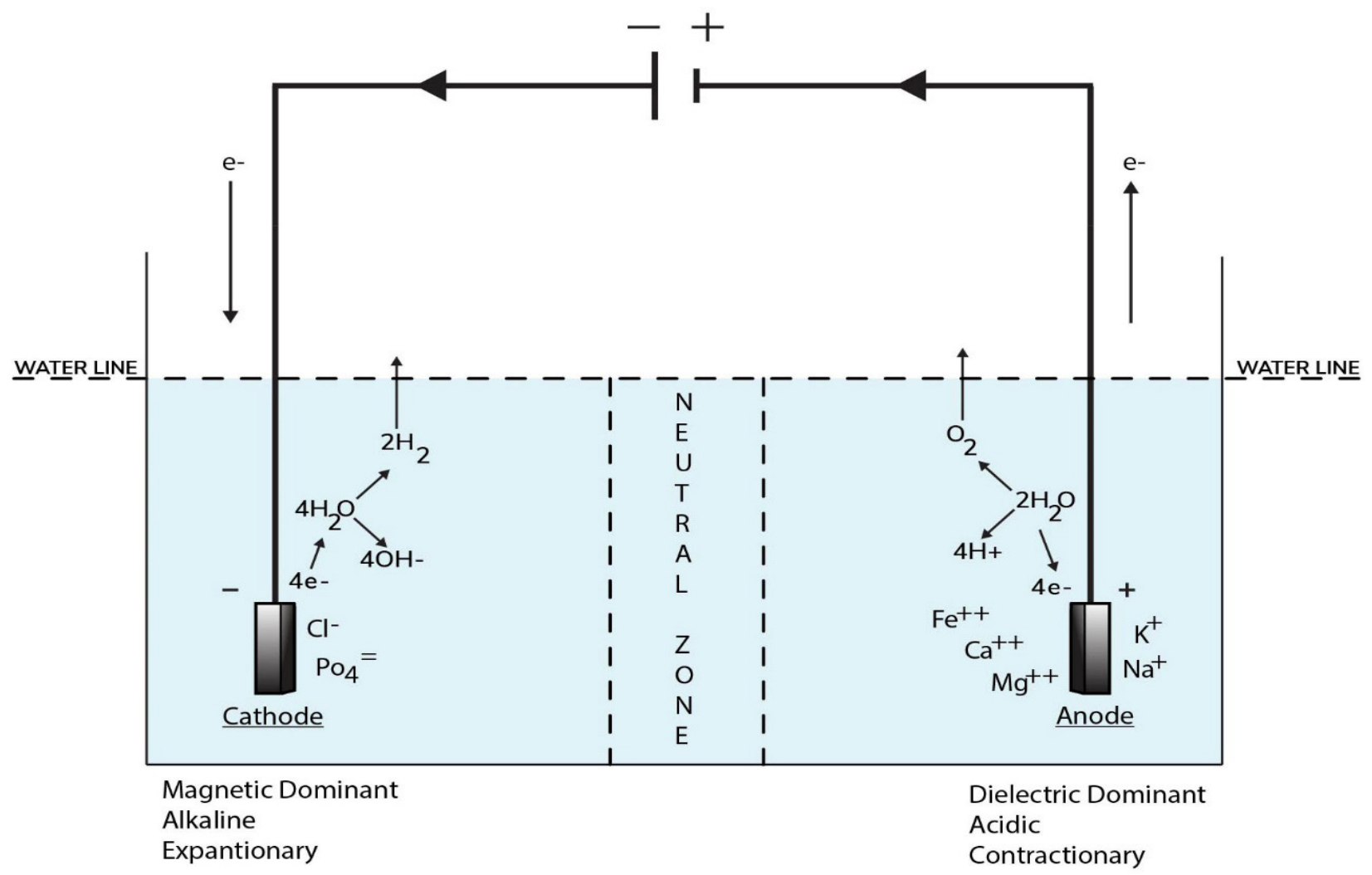

STEVE BARSHOV

Figure 5: DC-induced polarization and capacitance generation in an experimental water bath. A similar if not identical phenomenon is at play in the biologically closed electric circuits of living bodies. 
Soon after his discovery of lysosomes in the 1950s, biologistChristian de Duve, under the electronmicroscope, observed delivery of membrane-bound cellular material to lysosomes and coined the term autophagy to designate the orderly process by which cells self-digest [210, 211]. During autophagy acid is actively concentrated in lysosomes and catabolic enzymes activated not unlike processes that take place in the stomach. Autophagy not only culls aging and damaged cell structures but generates energy during periods of nutrient deficiency [212-224].

In addition to affecting the breakdown of intracellular materials, the lysosome is crucial for removing acid from the cytoplasm and keeping it in an alkaline $\mathrm{pH}$ range. Lysosomal function is essential for the maintenance of cellular and tissue health but there is a hitch: it is entirely dependent on aerobic magnetic-dominant energy generation. Acid is pumped into the lysosome by a strong electrochemical gradient driven by the ATPase enzyme system and when this malfunctions lysosomal acidification deteriorates $[225,226]$. This, in turn, leads back to the mitochondrion.

Mitochondria are multifunctional cellular clearing houses, involved not only in energy generation but synthesis of materials and waste processing. They are the cathodic hub of the cellular electric circuit responsible for ATP production through oxidative phosphorylation. When inflow of energetic currents across membrane ion channels diminishes mitochondria resort to alternate, less efficient energy pathways that generate acid and shift intracellular balance toward the anode. In extreme cases this destabilizes mitochondrial membranes with spillage of toxic materials into the cytoplasmic compartment which further impairs lysosomal function and autophagy $[227,235]$.

The presence of mitochondrial abnormalities in both immune and non-immune cell lines in various inflammatory conditions points to an energy deficiency adversely affecting functions of the entire internal digestive system. The most compelling evidence can be found in autoimmune disorders in which widespread mitochondrial defects are present in conditions like multiple sclerosis, rheumatoid arthritis, systemic lupus erythematosus, type I diabetes, Crohn's disease and more
[236-242]. Deficiencies in oxidative metabolism not only involve cells in the affected tissues but immune cells themselves including macrophages and PMNs, B-cells, and T-cells. These same mitochondrial defects have been described in Covid-19 infection [243, 244].

Not coincidentally, as we saw with migraine headache, defects in intracellular iron metabolism are widely present in inflammation. Iron is essential for various cellular processes like oxygen and lipid metabolism, oxidative phosphorylation, as well as DNA and protein synthesis. Mitochondria organize intracellular iron flux. Disturbed iron dynamics is also associated with impaired lysosomal acidification. Iron dysmetabolism, a proxy for deterioration of the magnetic field, has been implicated in various chronic conditions like atherosclerosis, diabetes, obesity, and non-alcoholic fatty liver disease [245-254].

Iron is said to produce toxicity by catalyzing generation of reactive oxygen species which damage lysosomal, cytoplasmic, nuclear and mitochondrial membranes throughlipid oxidation. In theacidic dielectricintracellular milieu iron itself is readily oxidized and appears to induce direct damage. In recent years an iron-dependent form of cell death called ferroptosis has been described in various disorders that appears to be induced by the dielectric field. In ferroptosis mitochondria are small and contracted with various morphologic abnormalities.

Once the dielectric field assumes dominance and metabolism shifts toward acid-generating pathways local tissue disruptions evolve that open the way to neoplastic transformation. Experiments by Warburg and Cori in the 1920 s found that cancer cells, as opposed to normal cells, consume large amounts of glucose and, in turn, produce large amounts of lactic acid [255-257]. The Warburg effect, a highly inefficient mode of energy generation, lies somewhere in the spectrum between cathodicallyinduced oxidative phosphorylation and anodic-related anaerobic glycolysis. Warburg implicated mitochondrial dysfunction. More recently it has been suggested that deficiencies in the mitochondrial electron transport chain or induction of enzyme systems are at play. The influence of the dielectric field is readily apparent in the loss of normal tissue architecture and cellular crowding (Figure $6)$. 
Figure 6. Breast histological specimens.
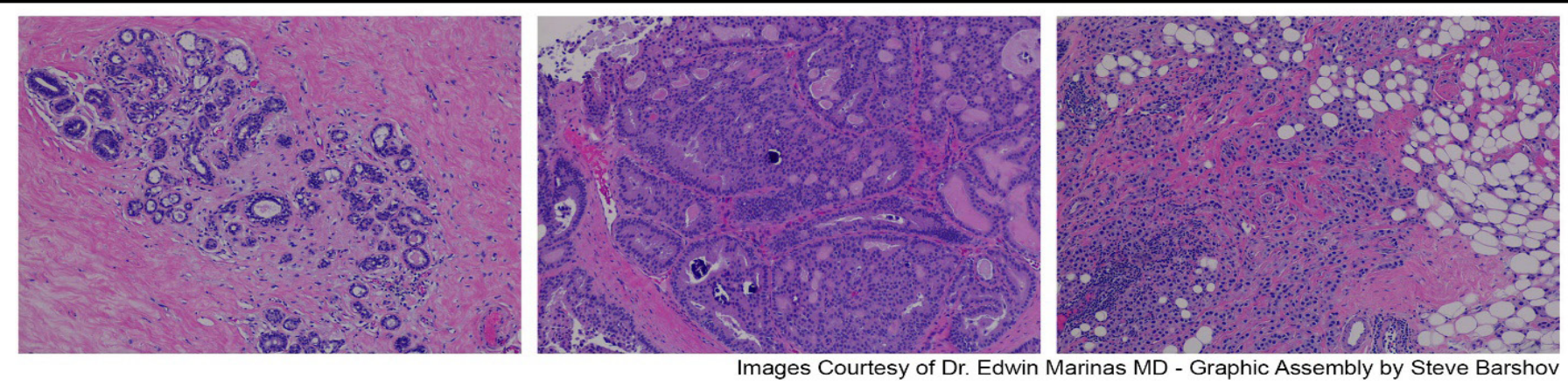

Figure 6: Three histological specimens depicting the progression from normal breast tissue (left) to atypical ductal proliferation (middle) to invasive cancer (right). As the cathodically induced magnetic field progressively weakens, cellular metabolism moves toward the anodic pole and increasing generation of acid products as typified by the Warburg phenomenon. Observe progressive loss of normal architecture and cellular crowding characteristic of dielectric-dominant field effects.

That all forms of inflammation represent primary energy deficiency states is supported by our experiences in treating inflammatory disorders of various etiologies by essentially the same means. In late 2019 we began treating a 30-year-old male with a 22-year history of type I diabetes with our light unit and vitamin D 30u/day. He had been taking $24 \mathrm{u}$ /day of long-acting and 25-30u/day of short-acting insulin. His HgbA1c levels were in the 8.0 range. Within weeks of initiating treatment, we observed marked fluctuations not only in blood glucose levels but insulin sensitivity. We soon realized that the long-acting insulin was acting to artificially alter insulin dynamics.

Over the next several months we weaned him off the long-acting preparation; in the same period, his shortacting insulin requirements climbed into the low40 's range. In the autumn of 2020 , we began low-dose hydroxychloroquine $200 \mathrm{mg} / \mathrm{wk}$ and over the next month observed a striking decrease in insulin requirements to the 30u/day range. His current requirements are in the 20-25u/d range with his most recent HgbA1c level at 6.7. We used this same regimen in individuals with early Covid-19 infection and observed prompt amelioration of symptoms. There is every reason to believe that such energy supplementation strategies will benefit other inflammatory states. This raises questions about the nature of the interaction between hydroxychloroquine and the dielectric field.

Throughout the $20^{\text {th }}$ century reports described beneficial effects of chloroquine (CQ) and hydroxychloroquine (HCO) in autoimmune and infectious conditions. General properties of the compounds include anti-inflammatory, anti-infective, immunomodulatory, anti-thrombotic as well as metabolic. Effects are seen in the blood, arterial wall, interstitial fluid space, and the intracellular compartment [259-262]. But how such widespread effects are mediated remain speculative.
Blood glucose-lowering effects of CQ/HCQ in type II diabetics were described in 1984. These substances have been shown to improve insulin resistance by enhancing glucose metabolism at the cellular level 263-265]. They improve lipid profiles by decreasing serum triglyceride and cholesterol level also likely related to metabolic alterations at the cellular level [266-268]. CQ/HCQ effects in the vascular system include increased endothelialdependent vasodilation and elevated nitric oxide in endothelial cells [269-274].

CQ/HCQ decrease pro-inflammatory cytokine release by macrophages while at the same time promoting phagocytosis; they inhibit pro-inflammatory $\mathrm{T}-$ and $\mathrm{B}$-cell receptor signaling, chemotaxis, and antigen presentation; they block pro-inflammatory T-cell proliferation and shift immune cell balance away from pro-inflammatory lines toward anti-inflammatory subsets. This is directly related to alterations in WBC metabolism with suppression of autophagy indicating a shift toward a more efficient energy-generating mode [275-285].

$\mathrm{CQ} / \mathrm{HCQ}$ actively accumulate in cells and most researchers believe their effects are mediated intracellularly. In both immune and non-immune cells, the primary effect of $\mathrm{CQ} /$ HCQ is to shift cytoplasmic $\mathrm{pH}$ into the alkaline range, in other words, from the anodic towards the cathodic pole of the biologically closed electric circuit. Alkalinization causes cellular metabolism to shift from catabolic to anabolic processes thereby inducing protein synthesis, repair of membranes, stabilization of DNA while at the same time diminishing lysosomal acidification and autophagy. In order to shut off one existing energygenerating pathway, i.e., autophagy, another energy source must become available.

$\mathrm{CQ} / \mathrm{HCQ}$ is said to induce alkalinization by accumulation in cells but this doesn't make sense. These compounds 
are weak bases but the magnitude of the effect is much greater than can be explained on the basis of their physical presence alone. They more likely act on the basis of field effects by enhancing dielectric capacitance in cells thereby inducing aether flux and flow of negatively-charged ion currents. Current treatments for inflammatory diseases revolve around modulation of pro-inflammatory immune pathways without ever addressing the underlying energy deficit. All future attempts at treatment of these states must address the energy equation which can be affected by external supplementation with radiant energy and enhancement of dielectric capacitance.

\section{Aether and the Continuum}

In this three-part series we have conclusively established the existence of a body-wide energetic economy based on aether-driven field dynamics between the dielectric, magnetic and radiant forms of energy. For the first time in medical history, we have described the integrated nexus of energy generation pathways that mediate all bodily functions. In the present paper we enumerated a host of pathologic conditions that ensue when energy imbalances between various organs and energy compartments arise for which medical science has no satisfactory explanation.

In the past several centuries medical scientists asserted the primacy of cellular and molecular mechanisms as a basis for all bodily functions. In recent decades such mechanisms have come under the aegis of the genome but this supposed unifying hypothesis has only complicated matters. Scientists remain unable to tie the myriad pathways and mechanisms into even a semblance of order. Our papers refute scientific atomism and confirm the primacy of the energy field and continuum as originally advanced 2400 years ago by Aristotle. Atomistic science is a 350-year failed legacy that has spawned a trail of disaster.

The experimental method is central to the atomistic delusion. All scientists bank on the notion that, given enough time and experiments, they will pull the rabbit out of the hat and tie everything together into a coherent picture. This has yet to happen. Instead, the experimental method became a tool used by academics to control intellectual discourse of modern cultures and to marginalize opposing perspectives. But from the onset, beginning with Harvey's fatal misinterpretation of cardiac function, the experimental method has been on terribly thin ice.

Since the mid-18 $8^{\text {th }}$ century, with philosophers like Hume and Kant, continuing through the writings of $20^{\text {th }}$ century science philosopher Karl Popper the limitations of the experimental method have been well-recognized. In a word, no single experiment affirms anything and no scientific theory, no matter how many experiments it draws upon, can ever be proven. A scientific theory is only valid until contradicting evidence emerges. Science advances not on the basis of proof but, rather, on refutation of pre-existing theories, which forms the basis of Popper's notion of falsifiability. When the heliocentric astronomical system replaced the Ptolemaic geocentric model in the $16^{\text {th }}$ century, it was based not so much on proof of planetary orbits around the sun but, rather, refutation that celestial bodies orbit the earth.

We have refuted the atomistic molecular and cellular hypothesis and shown the presence of a dynamic nexus of function that determines behaviors at the molecular and cellular levels and accounts for a plethora of phenomena not explainable on the basis of such processes. It is now incumbent upon academic scientists to refute the existence of the dynamic aether-based energy field we have described. In the absence of such refutation the continuum theory must be accepted as valid and fully determinate of all cellular and molecular events.

Barring plausible refutation of the continuum we can draw binding conclusions regarding $20^{\text {th }}$ century atomistic medical practices: first, all current medical therapeutics fail to address the fundamental dynamic disturbances that lead to the expression of various disease conditions. Secondly, medical scientists, as well as health care systems that employ such therapeutic approaches, must be implicated in the globally escalating epidemic of chronic disease. There is scant evidence to show they have been treating these chronic conditions correctly. Their therapies are only palliative in nature.

Finally, when theories are shown to be incorrect or incomplete it indicates they were in error from the beginning. That it required fourteen centuries for scientists to recognize the flawed assumptions underpinning Ptolemy's geocentric theory simply indicates that no one ever thought to question its factual basis. By the same token, this imputes a failure of oversight on the part of the academic medical community. Why weren't such issues deliberated decades ago when the first signs of cracks in the failing paradigm began to surface?

In order to begin to meaningfully address the burgeoning global problem of chronic disease, it is imperative that widescale dialogue ensue regarding implementation not only of novel therapeutic approaches but the consolidation of a new dynamic energy-based medicine to supersede the decadent and effete molecular and cellular approach. The King is dead.

Building on established principles, a series of papers, now in preparation, will examine the tragic mishandling of the Covid-19 pandemic by academic medical scientists, which has resulted in a large excess of morbidity and mortality, and which constitutes prima facie evidence of 
the failed atomistic paradigm. The pandemic has exposed all the cracks and flaws of medical science and organized healthcare. Increasing recognition of this evolving disaster has undermined confidence in the dictums of medical science not to mention threatening the survival of local and regional healthcare systems. Academia and organized healthcare will never be the same.

\section{References}

1. Pathophysiology of migraine: a disorder of sensory processing. Goadsby PJ, Holland PR, Martins-Oliveira $\mathrm{M}$ et al. Physiol Rev. 2017; 97(2): 553-622

2. A phase-by-phase review of migraine pathophysiology. Dodick DW. Headache. 2018 May; 58 Suppl 1: 4-16

3. The migraine theories of Liveing and Latham: a reappraisal. Weatherall MW. Brain. 2012; 135: 2560-2568

4. Clinical lecture on nervous or sick-headaches. Latham PW. Br Med J 1872; 1: 336-337,

5. A short history of nitroglycerine and nitric oxide in pharmacology and physiology. Marsh N, Marsh A. Clin Exp Pharmacol Physiol. 2000; 27(4): 313319

6. T. Lauder Brunton and amyl nitrate: a Victorian vasodilator. Fye WB. Circulation. 1986; 74(2): 222229

7. The effects of nitrogylcerin upon those who manufacture it. Laws GL. JAMA. 1898; 31: 793-94

8. Acute nitroglycerine poisoning. Rabinowitch IM. Can Med Assoc J. 1944; 50: 199-202

9. Nitric oxide is a key molecule in migraine and other vascular headaches. Olesen J, Thomsen LL, Iversen HK. Trends Pharmacol Sci. 1994; 15: 149153

10. Nitroglycerin as a provocative agent: in cluster headache. Ekbom K. Arch Neurol. 1968; 19: 487-493.

11. Experimental studies on headache. Pain sensitive structures of the head and their significance in headache. Ray BS, Wolff HG..Arch Surg. 1940; 41: 813-856
12. Propagation of spreading cortical depression. Leao AP, Morison RS. J Neurophysiol. 1945; 8: 33-45

13. Further observations on the spreading depression of activity in the cerebral cortex. Leao AAP J Neurophysiol. 1947: 10: 409-414

14. Migraine aura symptoms: duration, succession and temporal relationship to headache. Viana M, Linde M, Sances G et al. Cephalalgia. 2016; 36: 413-421

15. Clinical relevance of cortical spreading depression in neurological disorders: migraine, malignant stroke, subarachnoid and intracranial hemorrhage, and traumatic brain injury. Lauritzen M, Dreier JP, Fabricius M J Cereb Blood Flow Metab. 2011; 31: $17-35$

16. Migraine headache is present in the aura phase: a prospective study. Hansen JM, Lipton RB, Dodick DW. Neurology. 2012; 79: 2044-49

17. Cortical spreading depression triggers migraine attack: pro. Ayata C. Headache. 2010 Apr;50(4):72530

18. History of migraine with aura and cortical spreading depression from 1941 and onwards. Tfelt-Hansen PC. Cephalalgia. 2010; 30(7): 780-92

19. Cortical spreading depression and migraine. Charles AC, Baca SM. Nat Rev Neurol. 2013; 9(11): 637-44

20. Cortical excitability in chronic migraine. Coppola G, Schoenen J. Curr Pain Headache Rep. 2012; 16: 93-100

21. The emerging importance of cortical spreading depression in headache. Bolay $\mathrm{H}$, Moskowitz MA. Rev Neurol (Paris). 2005 Jul;161(6-7):655-7

22. Spreading depression as a preclinical model of migraine. Harriott AM, Takizawa T, Chung DY, Chen SP. J Headache Pain. 2019 May 2;20(1):45

23. Biphasic direct current shift, haemoglobin desaturation and neurovascular uncoupling in cortical spreading depression. Chang JC, Shook LL, Biag J et al. Brain. 2010; 133:996-1012

24. Cortical spreading depression and peri-infarct depolarization in acutely injured human cerebral 
cortex. Fabricius M, Fuhr S, Bhatia R et al. Brain. 2006; 129: 778-790

25. Cortical spreading depression recorded from the human brain using a multiparametric monitoring system. Mayevsky A, Doron A, Manor T et al. Brain Res. 1996; 740: 268-274

26. Spreading and synchronous depressions of cortical activity in acutely injured human brain. Strong AJ, Fabricius M, Boutelle MG et al. Stroke. 2002; 33: $2738-2743$

27. Neurovascular coupling during cortical spreading depolarization and depression. Østergaard L, Dreier JP, Hadjikhani N et al. Stroke. 2015 May; 46(5): 1392-401

28. Multi-modal MRI reveals the neurovascular coupling dysfunction in chronic migraine. $\mathrm{Hu} \mathrm{B}, \mathrm{Yu}$ Y, Dai YJ, Feng JH et al. Neuroscience. 2019 Nov 1; 419: 72-82

29. Abnormal neurovascular coupling as a cause of excess cerebral vasodilation in familial migraine. Staehr C, Rajanathan R, Postnov DD et al. Cardiovasc Res. 2020 Oct 1; 116(12): 2009-2020

30. Persistent ictal-like visual cortical excitability in chronic migraine. Chen WT, Wang SJ, Fuh JL et al. Pain. 2011; 152: 254-258

31. Orbitofrontal cortex involvement in chronic analgesic-overuse headache evolving from episodic migraine. Fumal A, Laureys S, Di Clemente L et al. Brain. 2006; 129(Pt 2): 543-50

32. Is there a persistent dysfunction of neurovascular coupling in migraine? Fabjan A, Zaletel M, Žvan B. Biomed Res Int. 2015; 2015: 574186

33. Nitric oxide is a key molecule in migraine and other vascular headaches. Olesen J, Thomsen LL, Iversen HK. Trends Pharmacol Sci. 1994; 15: 149-153

34. Nitric oxide supersensitivity: a possible molecular mechanism of migraine pain. Olesen J, Iversen HK, Thomsen LL. Neuroreport. 1993; 4: 1027-1030

35. The nitric oxide hypothesis of migraine and other vascular headaches. Olesen J, Thomsen LL, Lassen LH, Olesen IJ. Cephalalgia. 1995; 15: 94-100
36. Nitric oxide is a key molecule in migraine and other vascular headaches. Olesen J, Thomsen LL and Iversen H. Trends Pharmacol Sci. 1994; 15: 149-153

37. Nitric oxide supersensitivity: a possible molecular mechanism of migraine pain. Olesen J, Iversen HK and Thomsen LL. Neuroreport. 1993; 4: 1027-1030

38. Investigation of the pathophysiological mechanisms of migraine attacks induced by pituitary adenylate cyclase-activating polypeptide-Amin FM, Hougaard A, Schytz HW et al. Brain. 2014; 137: 779-794

39. Evidence for a vascular factor in migraine. Asghar MS, Hansen AE, Amin FM et al. Ann Neurol. 2011; 69: 635-645

40. CGRP may play a causative role in migraine. Lassen LH, Haderslev PA, Jacobsen VB et al. Cephalalgia. 2002; 22: 54-61

41. PACAP38 induces migraine-like attacks in patients with migraine without aura. Schytz HW, Birk S, Wienecke T et al. Brain. 2009;132:16-25

42. Prostaglandin I2 (epoprostenol) triggers migraine-like attacks in migraineurs. Wienecke T, Olesen J, Ashina M. Cephalalgia. 30: 179-190, 2010

43. Brain stem activation in spontaneous human migraine attacks. Weiller C, May A, Limmroth V et al. Nature Med. 1995; 1: 658-660

44. Allodynia and descending pain modulation in migraine: a resting state functional connectivity analysis. Schwedt TJ, Larsonprior L, Coalson RS et al. Pain Med. 2014; 15: 154-165

45. Atypical resting-state functional connectivity of affective brain regions in chronic migraine. Schwedt TJ, Schlaggar BL, Mar S et al. Headache. 2013; 53(5): 737-51

46. Altered functional magnetic resonance imaging resting-state connectivity in periaqueductal gray networks in migraine. Mainero C, Boshyan J, Hadjikani N. Neurol. 2011: 70(5): 838-45

47. Chronic migraine: a process of dysmodulation and sensitization. Su M, Yu S. Molecular Pain. 2018; $14: 1-10$ 
48. Brainstem dysfunction in chronic migraine as evidenced by neurophysiological and positron emission tomography studies. Aurora SK, Barrodale PM, Tipton RL, Khodavirdi A. Headache. 2007; 47: 996-1003

49. Brain stem activation in spontaneous human migraine attacks. Weiller C, May A, Limmroth V et al. Nature Med. 1995; 1:658-660

50. Chronic migraine: a process of dysmodulation and sensitization. Su M, Yu S Molecular Pain. 2018; 14:1-10

51. Periaqueductal gray matter dysfunction in migraine: cause or the burden of illness? Welch KM, Nagesh V, Aurora SK and Gelman N. Headache. 2001; 41: 629-637

52. Iron accumulation in deep brain nuclei in migraine: a population-based magnetic resonance imaging study. Kruit MC, Launer LJ, Overbosch J. Cephalalgia. 2009; 29(3): 351-59

53. Iron accumulation in pain-regulatory nuclei in episodic migraine and chronic daily headache by MRI. Tepper SJ, Lowe MJ, Beall E et al. Headache. 2012; 52(2): 236-43

54. Iron deposition in periaqueductal gray matter as a potential biomarker for chronic migraine. Dominguez C, Lopez A, Ramos-Cabrer P et al. Neurol. $2019,92,1-10$

55. Iron deposits in periaqueductal gray matter are associated with poor response to onabotulinumtoxinA in chronic migraine. Domínguez Vivero C, Leira Y, Saavedra Piñeiro M et al. Toxins (Basel). 2020;12(8): 479

56. Iron deposition in pain-regulatory nuclei in episodic migraine and chronic daily headache by MRI. Tepper SJ, Lowe MJ, Beall E et al. Headache. 2012; 52(2): 236-43

57. Hereditary hemochromatosis in two cousins with cluster headache. Stovner LJ, Hagen K, Waage A, Bjerve KS. Cephalalgia. 2002; 22(4): 317-19

58. High headache prevalence among women with hemochromatosis: the Nord-Trondelag health study. Hagen K, Stovner LJ, Asberg A et al. Neurol. 2002; 51(6):786-89
59. The liver: conductor of systemic iron balance. Meynard D, Babitt JL, Lin HY. Blood. 2014 Jan 9;123(2):168-76

60. The liver in regulation of iron homeostasis. Rishi G, Subramaniam VN. Am J Physiol Gastrointest Liver Physiol. 2017 Sep 1; 313(3): G157-G165

61. On iron metabolism and its regulation. Vogt AS, Arsiwala T, Mohsen M et al. Int J Mol Sci. 2021 Apr 27;22(9):4591

62. Migraine attacks as a result of hypothalamic loss of control. Stankewitz A, Keidel L, Rehm M, et al. Neuroimage Clin. 2021 Aug 16; 32: 102784

63. Migraine Pathophysiology. Qubty W, Patniyot I. Pediatr Neurol. 2020; 107: 1-6

64. Hypothalamic activation in spontaneous migraine attacks. Denuelle M, Fabre N, Payoux P et al. 2007; 47(10): 1418-26

65. Positron emission tomography studies in headache. Diener HC. Headache. 1997; 37(10): 622-5

66. Hypothalamic regulation of headache and migraine. May A, Burstein R. Cephalalgia. 2019 Nov; 39(13): 1710-1719

67. The Integrative Actions of the Nervous System. Charles Sherrington. Charles Scribner's Sons, New York. 1906

68. Migraine: a disorder of metabolism? Kokavec A. Med Hypotheses. 2016; 97: 117-130

69. Migraine exacerbation during Ramadan fasting. Abu-Salameh I, Plakht Y, Ifergane G Headache Pain. 2010; 11(6): 513-517

70. Worsening of migraine headache with fasting $\mathrm{Ra}-$ madan. Al-Hashel JY, Abokalawa F, Toma R et al. Clin Neurol Neurosurg. 2021; 25(3): 212-217

71. How does fasting trigger migraine? A hypothesis. Dalkara T, Kiliç K. Curr Pain Headache Rep. 2013 Oct; 17(10): 368 .

72. The association between migraine and physical exercise. Amin FM, Aristeidou S, Baraldi C et al. Headache Pain. 2018 Sep 10; 19(1): 83

73. Trigger factors in migraine patients. Mollaoglu M. 
J Health Psychol. 2013; 18(7): 984-94

74. Trigger factors in migraine patients. Fukui PT, Gonçalves TR, Strabelli CG et al. Arq Neuropsiquiatr. 2008; 66(3A): 494-99

75. Triggers, protectors, and predictors in episodic migraine. Marmura MJ. Curr Pain Headache Rep. 2018; 22(12): 81

76. Gut-brain axis and migraine headache: a comprehensive review. Arzani M, Jahromi SR, Ghorbani Z et al. J Headache Pain. 2020 Feb 13; 21(1): 15

77. Gut/brain axis and the microbiota. Mayer EA, Tillisch K, Gupta A. J Clin Invest. 2015; 125(3): 926-938

78. What the gut can teach us about migraine. Hindiyeh N, Aurora SK. Curr Pain Headache Rep. 2015: 19(7): 33

79. Comorbidity of headache and gastrointestinal complaints. The Head-HUNT Study. Aamodt AH, Stovner LJ, Hagen K, Zwart JA. Cephalalgia. 2008 28(2): 144-151

80. Gastrointestinal disorders associated with migraine: a comprehensive review. Cámara-Lemarroy CR, Rodriguez-Gutierrez R et al. World J Gastroenterol. 2016; 22(36): 8149-60

81. Comorbidity of gastrointestinal disorders, migraine, and tension-type headache: a cross-sectional study in Iran. Martami F, Ghorbani Z, Abolhasani M et al. Neurol Sci. 2018; 39(1): 63-70

82. Gut microbiota dysbiosis enhances migraine-like pain via TNF-alpha upregulation. Tang Y, Liu S, Shu H et al. Mol Neurobiol. 2020 Jan; 57(1): 461468

83. Migraine without aura and subclinical atherosclerosis in young females: is gut microbiota to blame? Georgescu D, Iurciuc MS, Ionita I et al. Medicina (Kaunas). 2019 Dec 16; 55(12): 786

84. Comorbidity of headache and functional constipation in children: a cross-sectional survey. Inaloo S, Dehghani SM, Hashemi SM et al. Turk J Gastroenterol. 2014; 25(5): 508-511

85. Increased prevalence of migraine in patients with uninvestigated dyspepsia referred for open-access upper gastrointestinal endoscopy. Meucci G, Radaelli F, Prada A et al. Endoscopy. 2005 37(7): 622-25

86. Evaluation of the relationship between migraine disorder and oral comorbidities: multicenter randomized clinical trial. Peşkersoy C, Peker Ş, Kaya A et al. Turk J Med Sci. 46(3): 712-718

87. Association between helicobacter pylori infection and migraine: a meta-analysis. Su J, Zhou XY, Zhang GX. World J Gastroenterol. 2014; 20(40): 14965-972

88. Is helicobacter pylori the infectious trigger for headache? a review. Savi L, Ribaldone DG, Fagoonee S, Pellicano R et al. Infect Disord Drug Targ. 2013; 13(5): 313-317

89. Migraine, fibromyalgia, and depression among people with IBS: a prevalence study. Cole JA, Rothman KJ, Cabral HJ et al. BMC Gastroenterol. 2006; 6(1): 26

90. irritable bowel syndrome and migraine: bystander or partners? Chang FY, Lu CL. J Neurogastroenterol Motil. 2013; 19(3): 301-311

91. Association between migraine and celiac disease: results from a preliminary case-control and therapeutic study. Gabrielli M, Cremonini F, Fiore G et al. Am J Gastroenterol. 2003; 98(3): 625-629

92. The neurologic profile of children and adolescents with inflammatory bowel disease. Ben-Or O, Zelnik N, Shaoul R et al. J Child Neurol. 2015; 30(5): 551-557

93. Peripheral neuropathy and neurological disorders in an unselected Brazilian population-based cohort of IBD patients. Oliveira GR, Teles BC, Brasil EF et al. Inflamm Bowel Dis. 2008; 14(3): 389-95

94. Migraine prevalence in inflammatory bowel disease patients: a tertiary-care Centre cross-sectional study. Moisset X, Bommelaer G, Boube et al. Eur J Pain. 2017; 21(9): 1550-1560

95. Concomitant functional gastrointestinal symptoms influence psychological status in Korean migraine patients. Park JW, Cho YS, Lee SY et al. Gut Liver. 2013; 7(6): 668-674 
96. Globus and headache: common symptoms of the irritable bowel syndrome. Watson WC, Sullivan SN, Corke M, Rush D. Can Med Assoc J. 1978; 118(4): 387-388

97. Association of Gastrointestinal Functional Disorders and Migraine Headache: a Population Base study. Lankarani KB, Akbari M, Tabrizi R. Mid-East J Dig Dis. 2017; 9(3): 139-145

98. Association between migraine and irritable bowel syndrome: a population-based retrospective cohort study. Lau CI, Lin CC, Chen WH et al. Eur J Neurol. 2014; 21(9):1198-1204

99. The Foundations of Chinese Medicine: A Comprehensive Text for Acupuncturists and Herbalists Giovanni Maciocia. Elsevier. 2005

100. On the motion of blood in the veins. Lord Cohen of Birkenhead. Br Med J. 1971; 3(5774): 551-557

101. Posterior reversible encephalopathy syndrome: a review. Shankar J, Banfield J. Can Assoc Radiol J. 2017 May; 68(2): 147-153

102. Posterior reversible encephalopathy syndrome. Fischer M, Schmutzhard E. J Neurol. 2017 Aug; 264(8): 1608-1616.

103. Posterior reversible encephalopathy syndrome. Liman TG, Siebert E, Endres M. Curr Opin Neurol. 2019 Feb; 32(1): 25-35.

104. Posterior reversible encephalopathy syndrome in eclampsia. Garg RK, Kumar N, Malhotra HS. Neurol India 2018 Sep-Oct; 66(5): 1316-1323

105. Posterior reversible encephalopathy syndrome (PRES): pathophysiology and neuroimaging. Anderson RC, Patel V, Sheikh-Bahaei N et al. Front Neurol. 2020 Jun 16;11:463

106. The imaging spectrum of posterior reversible encephalopathy syndrome: A pictorial review. Brady E, Parikh NS, Navi BB, Gupta A, Schweitzer AD. Clin Imaging. 2018 47: 80-89

107. Risk factors for poor outcome in posterior reversible encephalopathy syndrome: systematic review and meta-analysis. Chen Z, Zhang G, Lerner A, Wang AH, Gao B, Liu J. Quant Imaging Med Surg. 2018 May; 8(4): 421-432
108. Controversy of posterior reversible encephalopathy syndrome: what have we learnt in the last 20 years? Gao B, Lyu C, Lerner A. J Neurol Neurosurg Psych. 2018 Jan; 89(1): 14-21

109. Posterior reversible encephalopathy syndrome and takotsubo cardiomyopathy associated with lenvatinib therapy for thyroid cancer: a case report and review. Chae YK, Chiec L, Adney SK, Waitzman J, Costa R, Carneiro B, Matsangou M, Agulnik M, Kopp P. Oncotarget. 2018 Jun 15; 9(46): 28281-28289

110. Posterior reversible encephalopathy syndrome-an under recognized manifestation of chronic kidney disease. Kute VB, Trivedi HL, Shah PR, Gumber MR, Patel HV, Vanikar AV. Indian J Crit Care Med. 2013 Sep; 17(5): 318-20

111. Takotsubo cardiomyopathy. Coons JC, Barnes M, Kusick K. Am J Health Syst Pharm. 2009 Mar 15; 66(6): 562-6

112. Evaluation of Neuroimaging Findings of Central Nervous System Complications in Heart Transplant Recipients. Turnaoglu H, Agildere AM, Kural Rahatli F, Yildirim Donmez F, Ocal R, Sezer T, Can U, Sezgin A, Aslamaci S. Exp Clin Transplant. 2018 May 23; pp 1-9

113. Idiopathic intracranial hypertension. Thurtell MJ. Continuum (Minneapolis). 2019 Oct; 25(5): 1289-1309

114. Understanding idiopathic intracranial hypertension: mechanisms, management, and future directions. Markey KA, Mollan SP, Jensen RH, Sinclair AJ. Lancet Neurol. 2016 Jan; 15(1): 78-91

115. Idiopathic intracranial hypertension: update on diagnosis and management. Wakerley BR, Mollan SP, Sinclair AJ. Clin Med (Lond). 2020 Jul; 20(4): 384-388

116. Idiopathic intracranial hypertension. Boyter E.JAAPA..2019; 32(5): 30-35

117. Review: pathophysiology of intracranial hypertension and noninvasive intracranial pressure monitoring. Canac N, Jalaleddini K, Thorpe SG et al. Fluids Barriers CNS. 2020 Jun 23; 17(1): 40

118. Anatomy and physiology of cerebrospinal fluid. 
Sakka L, Coll G, Chazal J. Eur Ann Otorhin Head Neck Dis. Dec; 128(6): 309-16

119. Recent insights into a new hydrodynamics of the cerebrospinal fluid. Bulat M, Klarica M. Brain Res Rev. 2011 Jan 1; 65(2): 99-112

120. Evaluation of the production and absorption of cerebrospinal fluid. Miyajima M, Arai H Neurol Med Chir (Tokyo). 2015; 55(8): 647-56

121. Cerebrospinal fluid dynamics and intracranial pressure elevation in neurologic diseases. Bothwell SW, Janigro D, Patabendige A. Fluids Barriers CNS. 2019; 16(1): 9

122. Recent insights into the hydrodynamics of the cerebrospinal fluid. Bulat M, Klarica M. Brain Res Rev. 2011 Jan 1; 65(2): 99-112

123. Cerebrospinal fluid circulation: what do we know and how do we know it? Khasawneh AH, Garling RJ, Harris CA. Brain Circ. 2018; 4(1): 1418

124. Maternal mortality from preeclampsia/eclampsia. Ghulmiyyah L, Sibai B. Semin Perinatol. 2012 Feb; 36(1): 56-9

125. Pre-eclampsia: clinical manifestations and molecular mechanisms. Baumwell S, Karumanchi SA. Nephron Clin Pract. 2007; 106(2): c72-81

126. Long-term consequences of the posterior reversible encephalopathy syndrome in eclampsia and preeclampsia: a review of the obstetric and nonobstetric literature. Postma IR, Slager S, Kremer HP, de Groot JC, Zeeman GG. Obstet Gynecol Surg. 2014; 69(5): 287-300

127. The role of interleukins in preeclampsia: A comprehensive review. Bellos I, Karageorgiou V, Kapnias D, Karamanli KE, Siristatidis C. Am J Reprod Immunol. 2018 Sep 28: e13055

128. Regional changes of placental vascularization in preeclampsia: a review. Sahay AS, Sundrani DP, Joshi SR. IUBMB Life. 2015 Aug; 67(8): 619-25

129. Determinants of placental vascularity. Torry DS, Hinrichs M, Torry RJ. Am J Reprod Immunol. 2004 Apr; 51(4): 257-68
130. Incidence and prognosis of intraabdominal hypertension in a mixed population of critically ill patients: a multiple-center epidemiological study. Malbrain ML, Chiumello D, Pelosi P, Bihari D, Innes R, Ranieri VM, Del Turco M, Wilmer A, Brienza N, Malcangi V, Cohen J, Japiassu A, De Keulenaer BL, Daelemans R, Jacquet L, Laterre PF, Frank G, de Souza P, Cesana B, Gattinoni L. Crit Care Med. 2005 Feb; 33(2): 315-22

131. Elevated intra-abdominal pressure in acute decompensated heart failure: a potential contributor to worsening renal function? Mullens W, Abrahams Z, Skouri HN, Francis GS, Taylor DO, Starling RC, Paganini E, Tang WH. J Am Coll Cardiol. 2008 Jan 22; 51(3): 300-06

132. Cardiorenal interactions: insights from the ESCAPE trial. Nohria A, Hasselblad V, Stebbins A, Pauly DF, Fonarow GC, Shah M, Yancy CW, Califf RM, Stevenson LW, Hill JA. J Am Coll Cardiol. 2008; 51(13): 1268-74

133. Importance of venous congestion for worsening of renal function in advanced decompensated heart failure. Mullens W, Abrahams Z, Francis GS, Sokos G, Taylor DO, Starling RC, Young JB, Tang WH. J Am Coll Cardiol. 2009 Feb 17; 53(7): 589-96

134. The influence of venous pressure on the isolated mammalian kidney. Winton FR. J Physiol. 1931 Jun 6; 72(1): 49-61

135. Renal interstitial pressure and sodium excretion during renal vein constriction. Burnett JC, Knox FG. Am J Physiol. 1980 Apr; 238(4): F279-82

136. Segmental analysis of sodium reabsorption during renal vein constriction. Burnett JC Jr, Haas JA, Knox FG. Am J Physiol. 1982 Jul; 243(1): F1922

137. Raised venous pressure: a direct cause of renal sodium retention in oedema? Firth JD, Raine AE, Ledingham JG. Lancet. 1988 May 7;1(8593):1033-5

138. Cardiorenal syndrome: An overview. Ronco C, Bellasi A, Di Lullo L. Adv Chronic Kidney Dis. 2018; 25(5): 382-390 
139. Cardiorenal syndrome: pathophysiolog. Kumar U, Wettersten N, Garimella PS. Cardiol Clin. 2019; 37(3): 251-265

140. Epidemiology of cardiorenal syndrome. Uduman J. Adv Chronic Kidney Dis. 2018; 25(5): 391399

141. Acute cardiorenal syndrome: mechanisms and clinical implications. Thind GS, Loehrke M, Wilt JL. Cleve Clin J Med. 2018 Mar; 85(3): 231-239

142. Cardiorenal syndrome in acute kidney injury. Di Lullo L, Reeves PB, Bellasi A, Ronco C. Semin Nephrol. 2019 Jan; 39(1): 31-40

143. Cardiorenal syndrome. Ronco C, Haapio M, House AA, Anavekar N, Bellomo R. J Am Coll Cardiol. 2008 Nov 4; 52(19): 1527-39

144. Pathophysiology of the cardiorenal syndromes: executive summary from the eleventh consensus conference of the Acute Dialysis Quality Initiative (ADQI). McCullough PA, Kellum JA, Haase $\mathrm{M}$ et al. Contrib Nephrol. 2013; 182: 82-98

145. The epidemiology of epilepsy. Past, present, and future. Berg AT, Testa FM, Levy SR, Shinnar S. Neurol Clin. 1996 May; 14(2): 383-98

146. Classification of epilepsies and seizures: historical perspective and future directions. Berg AT, Cross JH. Handb Clin Neurol. 2012; 107: 99-111

147. Concepts in classification and their relevance to epilepsy. Berg AT, Blackstone NW. Epilepsy Res. 2006; 70(Suppl 1): S11-19

148. Some common issues in the use of antiepileptic drugs. Asconapé JJ. Semin Neurol. 2002 Mar;22(1):27-39

149. Drug-resistant epilepsy. Kwan P, Schacter SC, Brodie MJ. NEJM. 2011; 365(10): 919-26.

150. A brief history of epilepsy and its therapy in the Western Hemisphere. Gross RA. Epilepsy Res. 1992; 12(2): 65-74

151. All epilepsy is one. Mackay RP, Arch Neurol. 1960 Mar: 237-46

152. Slow periodic activity in the longitudinal hippo- campal slice can self-propagate non-synaptically by a mechanism consistent with ephaptic coupling. Chiang CC, Shivacharan RS, Wei X et al. J Physiol. 2019; 597(1): 249-269

153. Sleep-wake distribution and circadian patterns of epileptic seizures in children. Gurkas E, Serdaroglu A, Hirfanoglu T et al. Eur J Pediatr Neurol. 2016; 20(4): 549-54

154. Circadian patterns of pediatric seizures. Loddenkemper T, Vendrame M, Zarowski M et al. Neurol. 2011; 76(2): 145-53

155. Epilepsy: Ever-changing states of cortical excitability. Badawy RA, Freestone DR, Lai A, Cook MJ. Neurosci. 2012 Oct; 222:89-99

156. Cortical hyperexcitability and epileptogenesis: understanding the mechanisms of epilepsy. Part 1. Badawy RA, Harvey AS, Macdonell RA. J Clin Neurosci. 2009; 16(3): 355-65

157. Cortical hyperexcitability and epileptogenesis: understanding the mechanisms of epilepsy. Part 2. Badawy RA, Harvey AS, Macdonell RA. J Clin Neurosci. 2009; 16(4): 485-500

158. Effects of sleep and sleep stage on epileptic and nonepileptic seizures. Bazil CW, Walczak TS. Epilepsia. 1997; 38(1): 56-62

159. Synchronized sleep oscillations and their paroxysmal developments. Steriade M, Contreras D, Amzica F. Trends Neurosci. 1994 May; 17(5): 199-208

160. Stress, the hippocampus, and epilepsy. Joëls $M$. Epilepsia. 2009 Apr; 50(4): 586-97

161. Relation between stress-precipitated seizures and the stress response in childhood epilepsy. van Campen JS, Jansen FE, Pet MA et al. Brain. 2015; 138(Pt 8): 2234-48

162. Early life stress in epilepsy: a seizure precipitant and risk factor for epileptogenesis. van Campen JS, Jansen FE, de Graan PN et al. Epilepsy Behav. 2014; 38: 160-71

163. The neuroendocrinology of stress: a never-ending story. Lightman SL. J Neuroendocrinol. 2008; 20(6): 880-84 
164. Depression in epilepsy: prevalence, clinical semiology, pathologic mechanisms, and treatment. Kanner AM. Biol Psychia. 2003; 54(3): 388-98

165. The peri-ictal state: cortical excitability changes within 24h of a seizure. Badawy R, Macdonell R, Jackson G, Berkovic S. Brain. 2009; 132(4): 1013-21

166. Dynamics of convulsive seizure termination and postictal generalized EEG suppression. Bauer PR, Thijs RD, Lamberts RJ et al. Brain. 2017; 140(3): 655-68

167. Postictal generalized EEG suppression and SUDEP: a review. Rajakulendran S, Nashef L. J Clin Neurophysiol. 2015; 32(1): 14-20

168. Sudden unexpected deaths in epileptics--a literature review. McGugan EA. Scot Med J. 1999: 44(5): 137-39

169. Sudden unexpected death in epileptics following sudden, intense, increases in geomagnetic activity: prevalence of effect and potential mechanisms. Persinger MA, Psych C. Int J Biometeorol. 1995 May; 38(4): 180-7

170. Interictal cardiovascular autonomic responses in patients with epilepsy. Isojärvi JI, Ansakorpi H, Suominen K et al. Epilepsia. 1998 Apr; 39(4): 420-6

171. Autonomic symptoms during epileptic seizures. Baumgartner C, Lurger, Luetmezer F Epilept Disord. 2001 Sep; 3(3): 103-16

172. Cardiac arrhythmias during or after epileptic seizures. Van der Lende M, Surges R, Sander JW, Thijs RD. J Neurol Neurosurg Psychia. 2016; 87(1): 69-74

173. Potentially high-risk cardiac arrhythmias with focal to bilateral tonic-clonic seizures and generalized tonic-clonic seizures are associated with the duration of periictal hypoxemia. Park KJ, Sharma G, Kennedy JD, Seyal M Epilepsia. 2017; 58(12): 2164-71

174. Autonomic changes with seizures correlate with postictal EEG suppression. Poh MZ, Loddenkemper T, Reinsberger C et al. Neurology. 2012; 78(23): 1868-76
175. Photic- and pattern-induced seizures: a review for the Epilepsy Foundation of America Working Group. Fisher RS, Harding G, Erba G et al. Epilepsia. 2005;46(9):1426-41

176. Gamma-band phase clustering and photosensitivity: is there an underlying mechanism common to photosensitive epilepsy and visual perception? Parra J, Kalitzin SN, Iriarte J et al. Brain. 2003; 126(Pt 5): 1164-72

177. MEG and EEG in epilepsy. Barkley GL, Baumgartner C. J Clin Neurophysiol. 2003 May-Jun; 20(3): 163-78

178. Transition to seizure in photosensitive epilepsy. Lopes da Silva FH, Harding GF. Epilepsy Res. 2011 Dec; 97(3): 278-82

179. Seasonality of birth in epilepsy: a Danish study. Procopio M, Marriott PK. Acta Neurol Scand. 1998 Nov; 98(5): 297-301

180. Seasonality of birth in epilepsy: a Southern Hemisphere study. Procopio M, Marriott PK, Davies RJ. Seizure. 2006 Jan; 15(1): 17-21

181. Seeing the light? Seizures and sunlight. Baxendale S. Epilepsy Res. 2009; 84(1): 72-76

182. Disturbance of Function (Functio Laesa): The Legendary Fifth Cardinal Sign of Inflammation, Added by Galen to the Four Cardinal Signs of Celsus. Rather LJ. Bull NY Acad Med. 43(3), 1971 pp. 303-322

183. Chronic inflammation in multiple sclerosisseeing what was always there. Matthews PM. Nat Rev Neurol 2019 Oct; 15(10): 582-593

184. Local inflammation in chronic upper airway disease. Calus L, Van Zele T, Derycke L et al. Curr Pharm Des 2012; 18(16): 2336-46

185. Chronic inflammation in asthma: a contest of persistence vs resolution. Van Hove CL, Maes T, Joos GF, Tournoy KG. Allergy. 2008 Sep; 63(9): 1095-109

186. Chronic obstructive pulmonary disease and cardiovascular disease: role of the systemic inflammation. Rossi FF, Pedone C, Antonelli Incalzi R. Rec Prog Med. 2011 Mar; 102(3): 109-13 
187. Chronic inflammation in end-stage renal disease and dialysis. Cobo G, Lindholm B, Stenvinkel P. Nephrol Dial Transplant. 2018; 33(suppl_3): iii35-iii40

188. The impact of inflammation on metabolic regulation in chronic kidney disease: a review. Guarnieri G, Grassi G, Barazzoni R, Zanetti M, Biolo G. J Ren Nutr. 2005; 15(1): 121-4

189. Inflammation in chronic kidney disease: role in the progression of renal and cardiovascular disease. Silverstein DM. Pediatr Nephrol. 2009 Aug; 24(8): 1445-52

190. Inflammation-cause or consequence of heart failure or both? Van Linthout S, Tschöpe C Curr Heart Fail Rep. 2017; 14(4): 251-265

191. The biological role of inflammation in atherosclerosis. Wong BW, Meredith A, Lin D, McManus BM. Can J Cardiol. 2012 Nov-Dec; 28(6): 631-41

192. Immune-inflammation in atherosclerosis: a new twist in an old tale. Talepoor AG, Fouladseresht $\mathrm{H}$, Khosropanah S et al. Endocr Metab Immune Disord Drug Targets. 2020; 20(4): 525-45

193. Metabolism: the road to inflammation and atherosclerosis. Ali L, Schnitzler JG, Kroon J. Curr Opin Lipidol. 2018; 29(6): 474-80

194. Inflammation, a double-edge sword for cancer and other age-related diseases. Gupta SC, Kunnumakkara AB, Aggarwal S, Aggarwal BB. Front Immunol. 2018; 9: 2160.

195. Inflammation and cancer. Coussens LM, Werb Z. Nature. 2002; 420(6917): 860-67

196. Similarities and distinctions of cancer and immune metabolism in inflammation and tumors. Andrejeva G, Rathmell JC. Cell Metab. 2017; 26(1): 49-70

197. Inflammation and stroke: an overview. Anrather J, Iadecola C. Neurotherapeutics. 2016;13(4):661670

198. Inflammation in CNS neurodegenerative disorders. Stephenson J, Nutma E, van der Valk P, Amor S. Immunol. 2018; 154(2): 204-219
199. Inflammation and Parkinson's disease. Wersinger C, Sidhu A. Curr Drug Targets Inflamm Allergy. 2002 Sep; 1(3): 221-42

200. Diabetes mellitus and inflammation. Lontchi-Yimagou E, Sobngwi E, Matsha TE, Kengne AP. Curr Diab Rep. 2013; 13(3): 435-44

201. Inflammation, oxidative stress, apoptosis and autophagy in diabetes mellitus and diabetic kidney disease: the Four Horsemen of the Apocalypse. Turkmen K. Int Urol Nephrol. 2017; 49(5): 837844

202. Mast cells as key players in allergy and inflammation. González-de-Olano D, Álvarez-Twose I. J Investig Allergol Clin Immunol. 2018; 28(6): 365-378

203. Allergy and inflammation: an immunologic and therapeutic approach. Shukla S, Shukla H, Kumar S et al. Recent Pat Inflamm Aller Drug Discov. 2013; 7(2): 135-50

204. Inflammatory mechanisms: the molecular basis of inflammation and disease. Libby P. Nutr Rev. 2007 Dec; 65(12 Pt 2): S140-6

205. Metabolic regulation of inflammation. Gaber T, Strehl C, Buttgereit F. Nat Rev Rheumatol. 2017; 13(5): 267-279

206. Inflammation and its role in regeneration and repair. Cooke JP. Circ Res. 2019 Apr 12; 124(8): 1166-1168

207. Role of innate and adaptive immune mechanisms in cardiac injury and repair. Epelman S, Liu PP, Mann DL. Nat Rev Immunol. 2015 Feb; 15(2): 117-29

208. Neutrophil migration in infection and wound repair: going forward in reverse. De Oliveira S, Rosowski EE, Huttenlocher A. Nat Rev Immunol. 2016 May 27; 16(6): 378-91

209. Adaptive innate immunity or innate adaptive immunity? Černy J, Striž I. Clin Sci (Lond). 2019 Jul 17; 133(14): 1549-1565

210. Functions of lysosomes. De Duve C, Wattiaux R. Annu Rev Physiol. 1966; 28: 435-492. 
211. The lysosome turns fifty. De Duve C. Nat Cell Biol. 2005; 7: 847-849

212. Historical landmarks of autophagy research. Ohsumi Y. Cell. Res 2014. Jan; 24(1): 9-23.

213. Autophagy and energy metabolism. Yang J, Zhou R, Ma Z. Adv Exp Med Biol. 2019; 1206: 329-357

214. Autophagy and the immune system, Kuballa P, Nolte WM, Castoreno AB, Xavier RJ. Annu Rev Immunol. 2012; 30: 611-46

215. Autophagy in innate and adaptive immunity. $\mathrm{Xu}$ Y, Eissa NT. Proc Am Thorac Soc. 2010; 7(1): 2228

216. Autophagy in immunity and inflammation. Levine B, Mizushima N, Virgin HW. Nature. 2011; 469(7330): 323-35.

217. Autophagy mediates neutrophil responses to bacterial infection. Chargui A, El May MV. APMIS. 2014; 122(11): 1047-58

218. Autophagy and inflammation. Matsuzawa-Ishimoto Y, Hwang S, Cadwell K. Annu Rev Immunol. 2018; 36: 73-101

219. Autophagy and inflammation in ischemic stroke. Mo Y, Sun YY, Liu KY. Neural Regen Res. 2020; 15(8): 1388-1396

220. Autophagy and inflammation regulation in acute kidney injury. Gong L, Pan Q, Yang N Front Physiol. 2020; 11: 576463

221. Autophagy and kidney inflammation. Kimura T, Isaka Y, Yoshimori T. Autophagy. 2017; 13(6): 997-1003

222. Autophagy: the spotlight for cellular stress response. Ravanan P, Srikumar IF, Talwar P. Life Sci. 2017; 188: 53-67

223. Autophagy in chronic kidney diseases. Lin TA, Wu VC, Wang CY. Cells. 2019; 8(1): 61

224. Autophagy in diabetic neuropathy. Ding Y, Choi ME. J Endocrinol. 2015; 224(1): R15-30

225. Disorders of lysosomal acidification: the emerging role of v-ATPase in aging and neurodegenerative disease. Colacurcio DJ, Nixon RA.
Ageing Res Rev. 2016: 32: 75-88

226. The emerging roles of vacuolar-type ATPase-dependent lysosomal acidification in neurodegenerative diseases. Song Q, Meng B, Xu H, Mao Z. Transl Neurodegen. 2020; 9(1): 17

227. Inflammation and mitochondrial dysfunction: a vicious circle in neurodegenerative disorders? van Horssen J, van Schaik P, Witte M. Neurosci Lett. 2019; 710: 132931

228. Mitochondrial dysfunction as a trigger of innate immune responses and inflammation. West AP. Toxicology. 2017; 391: 54-63

229. Mitochondrial dysfunction and damage associated molecular patterns (DAMPS) in chronic inflammatory diseases. Dela Cruz CS, Kang MJ. Mitochondrion. 2018; 41: 37-44

230. Mitochondria and inflammation. Kolmychkova KI, Zhelankin AV, Karagodin VP, Orekhov AN. Patol Fiziol Eksp Ter. 2016; 60(4): 114-21

231. Mitochondria and the autophagy-inflammation-cell death axis in organismal aging. Green DR, Galluzzi L, Kroemer G. Science. 2011; 333(6046): 1109-12

232. Mitochondria and the link between neuroinflammation and neurodegeneration. Di Filippo M, Chiasserini D, Tozzi A et al. J Alzheimers Dis. 2010;20 Suppl 2: S369-79

233. Mitochondrial dysfunction in pathophysiology of heart failure. Zhou B, Tian R.J. Clin Invest. 2018; 128(9): 3716-3726

234. The interplay between inflammation, oxidative stress, DNA damage, DNA repair and mitochondrial dysfunction in depression. Czarny $\mathrm{P}$, Wigner P, Galecki P, Sliwinski T. Prog Neuropsychopharmacol Biol Psychiatry. 2018; 80(Pt C): 309-321

235. Mitochondrial dysfunction in obesity. de Mello $\mathrm{AH}$, Costa AB, Engel JDG, Rezin GT. Life Sci. 2018; 192: 26-32

236. Mitochondrial Dysfunction and Multiple Sclerosis. Peixoto de Barcelos I, Troxell RM, Graves JS. Biology (Basel). 2019 May 11; 8(2): 37 
237. Assessment of mitochondrial dysfunction in lymphocytes of patients with systemic lupus erythematosus. Perl A, Hanczko, Doherty E. Methods Mol Biol. 2012; 900: 61-89

238. Mitochondrial dysfunction in rheumatoid arthritis: A comprehensive analysis by integrating gene expression, protein-protein interactions and gene ontology data. Panga V, Kallor AA, Nair A, Harshan S, Raghunathan S. PLoS One. 2019 Nov 8; 14(11): e0224632

239. Hypoxia, mitochondrial dysfunction and synovial invasiveness in rheumatoid arthritis. Fearon U, Canavan M, Biniecka M, Veale DJ. Nat Rev Rheumatol. 2016 Jul; 12(7): 385-97

240. Mitochondrial dysfunction in diabetes: from molecular mechanisms to functional significance and therapeutic opportunities. Sivitz WI, Yorek MA. Antioxid Redox Signal. 2010; 12(4): 537-77

241. Mitochondrial impairment drives intestinal stem cell transition into dysfunctional Paneth cells predicting Crohn's disease recurrence. Khaloian S, Rath E, Hammoudi N, Gleisinger E et al. Gut. 2020 Nov; 69(11): 1939-1951

242. Mitochondrial dysfunction, persistent oxidative damage, and catalase inhibition in immune cells of naïve and treated Crohn's disease. Beltrán $\mathrm{B}$, Nos P, Dasị F, Iborra M et al. Inflamm Bowel Dis. 2010 Jan; 16(1): 76-86

243. Coronavirus (Covid-19) sepsis: revisiting mitochondrial dysfunction in pathogenesis, aging, inflammation and mortality. Shenoy S. Inflamm Res. 2020; 69(11): 1077-1085

244. Altered bioenergetics and mitochondrial dysfunction in monocytes in patients with Covid-19 pneumonia. Gibellini L, De Biasi S, Paolini A, Borella R et al. EMBO Mol Med. 2020; 12(12): e13001

245. Down the iron path: mitochondrial iron homeostasis and beyond. Dietz JV, Fox JL, Khalimonchuk O. Cells. 2021; 10(9): 2198

246. Mitochondrial mayhem: the mitochondrion as a modulator of iron metabolism and its role in disease. Huang ML, Lane DJ, Richardson DR. Antioxid Redox Signal. 2011; 15(12): 3003-19

247. Mitochondrial iron metabolism and its role in diseases. Gao J, Zhou Q, Wu D, Chen L. Clin Chim Acta. 2021; 513: 6-12

248. The molecular mechanisms of iron metabolism and its role in cardiac dysfunction and cardioprotection. Ravingerová T, Kindernay L, Barteková M et al. J Mol Sci. 2020; 21(21): 78

249. Mitochondrial iron metabolism and its role in neurodegeneration. Horowitz MP, Greenamyre JT. J Alzheimers Dis. 2010; 20 Suppl 2(Suppl 2): S551-68

250. The role of iron in hepatic inflammation and hepatocellular carcinoma Miyanishi K, Tanaka S, Sakamoto H, Kato J. Free Radic Biol Med. 2019; 133: 200-205

251. Role of iron in neurodegenerative diseases. Li K, Reichmann H. J Neural Transm (Vienna). 2016 Apr; 123(4): 389-99

252. Autophagy-dependent ferroptosis: machinery and regulation. Liu J, Kuang F, Kroemer G et al. Cell. Chem Biol 2020; 27(4): 420-435

253. Mitochondria regulation in ferroptosis. Wang H, Liu C, Zhao Y, Gao G. Eur J Cell Biol. 2020; 99(1): 151058

254. Ferroptosis: process and function. Xie Y, Hou W, Song X et al. Cell. Death Differ 2016; 23(3): 36979

255. The Warburg effect: 80 years on. Potter M, Newport E, Morten KJ. Biochem Soc Trans. 2016 Oct 15; 44(5): 1499-1505

256. Warburg Effect - a Consequence or the Cause of Carcinogenesis? Devic S. J Cancer. 2016 Apr 26; 7(7): 817-22

257. Understanding the Warburg effect: the metabolic requirements of cell proliferation. Vander Heiden MG, Cantley LC, Thompson CB. Science. 2009 May 22; 324(5930): 1029-33.

258. Hydroychloroquine: From malaria to autoimmunity. Ben-Zvi I, Kivity S, Langevitz P, Sho- 
enfeld Y. Clin Rev Allergy Immunol. 2012: 42(2): $145-53$

259. Current and Future use of chloroquine and hydrochloroquine in infectious, immune, neoplastic and neurological diseases: a mini-review. Plantane D, Koudriavtseva. Clin Drug Invest. 2018; 38(8): 653-71

260. Hydroxychloroquine in rheumatic autoimmune disorders and beyond. Nirk EL, Reggiori F, Mauthe M. EMBO Mol Med. 2020; 12(8): e12476

261. Therapy and pharmacological properties of hydroxychloroquine and chloroquine in treatment of systemic lupus erythematosus, rheumatoid arthritis and related diseases. Rainsford KD, Parke AL, Clifford-Rashotte M, Kean WF. Inflammopharmacology. 2015 Oct; 23(5): 231-69

262. In vivo chloroquine-induced inhibition of insulin degradation in a diabetic patient with severe insulin resistance. Blazar BR, Whitley $\mathrm{CB}$, Kitabchi AE, Tsai MY et al. Diabetes. 1984 Dec; 33(12): 1133-7

263. Hydroxychloroquine in decompensated, treatment-refractory noninsulin-dependent diabetes mellitus. A new job for an old drug? Quatraro A, Consoli G, Magno M, Caretta F. Ann Intern Med. 1990; 112(9): 678-81

264. Potential Effect of Hydroxychloroquine in Diabetes Mellitus: A Systematic Review on Preclinical and Clinical Trial Studies. Wondafrash DZ, Desalegn TZ, Yimer EM et al. J Diabetes Res. 2020 Feb 27; 2020: 5214751

265. Cholesterol-lowering effect of hydroxychloroquine in patients with rheumatic disease: reversal of deleterious effects of steroids on lipids. Wallace DJ, Metzger AL, Stecher VJ et al. Am J Med. 1990 Sep; 89(3): 322-6

266. Hydroxychloroquine reduces low-density lipoprotein cholesterol levels in systemic lupus erythematosus: a longitudinal evaluation of the lipid-lowering effect. Cairoli E, Rebella M, Danese N, Garra V et al. Lupus. 2012 Oct; 21(11): 1178-82.

267. Hydroxychloroquine use associated with impro- vement in lipid profiles in rheumatoid arthritis patients. Morris SJ, Wasko MC, Antohe JL, Sartorius JA. Arthritis Care Res (Hoboken). 2011 Apr; 63(4): 530-4

268. Hydroxychloroquine reverses platelet activation induced by human IgG antiphospholipid antibodies. Espinola RG, Pierangeli SS, Gharavi AE, Harris EN. Thromb Haemost. 2002; 87(3): 518-22

269. The protective effect of antimalarial drugs on thrombovascular events in systemic lupus erythematosus. Jung H, Raja B, Su J, Shariati-Sarabi Z et al. Arthritis Rheum. 2010 Mar; 62(3): 863-8

270. Chronic hydroxychloroquine improves endothelial dysfunction and protects kidney in a mouse model of systemic lupus erythematosus. Gómez-Guzmán M, Jiménez R, Romero $M$, Sánchez $M$ et al. Hypertension. 2014 Aug; 64(2): 330-7

271. Early treatment with hydroxychloroquine prevents the development of endothelial dysfunction in a murine model of systemic lupus erythematosus. Virdis A, Tani C, Duranti E, Vagnani S et al. Arthritis Res Ther. 2015 Oct 6; 17: 277

272. Chloroquine and hydroxychloroquine are associated with reduced cardiovascular risk: a systematic review and meta-analysis. Liu D, Li X, Zhang Y, Kwong J, Li L et al. Drug Des Devel Ther..2018 Jun 11; 12: 1685-1695

273. Chloroquine stimulates nitric oxide synthesis in murine, porcine, and human endothelial cells. Ghigo D, Aldieri E, Todde R, Costamagna C. J Clin Invest. 1998 Aug 1; 102(3): 595-605

274. Chloroquine autophagic inhibition rebalances Th17/Treg-mediated immunity and ameliorates systemic lupus erythematosus. An N, Chen Y, Wang C et al. Cell Physiol Biochem. 2017; 44(1): $412-22$

275. Chloroquine \& Hydroxychloroquine equally affect tumor necrosis factor-a, interleukin 6 \& interferon-y by peripheral blood mononuclear cells. Van den Borne BEEM, Dijkmans BAC, De Rooij HH. J Rheumatol. 1997

276. Chloroquine inhibits processing of tumor ne- 
crosis factor in lipopolysaccharide-stimulated RAW 264.7 macrophages. Jeong JY, Jue DM. J Immunol. 1997 May 15; 158(10): 4901-7

277. Chloroquine inhibits production of TNF-alpha, IL-1beta and IL-6 from lipopolysaccharide-stimulated human monocytes/macrophages by different modes. Jang C-H, Choi J-H, Byun M-S, Jue D-M. Rheumatology (Oxford). 2006 Jun; 45(6): 703-10

278. Killing of Escherichia coli by Crohn's Disease Monocyte-derived Macrophages and Its Enhancement by Hydroxychloroquine and Vitamin D. Flanagan PK, Chiewchengchol D, Wright H, Edwards SW. Inflamm Bowel Dis. 2015 Jul; 21(7): 1499-510

279. Chloroquine inhibits tumor necrosis factor production by human macrophages in vitro. Picot S, Peyron F, Vuillez JP, Polack B, Ambroise-Thomas P J. Infect Dis. 1991; 164: 830
280. Chloroquine and hydroxychloroquine equally affect tumor necrosis factor-a, interleukin 6 , and interferon-c production by peripheral blood mononuclear cells. Van Den Borne BEEM, Dijkmans BAC, De Rooij HH, Le Cessie S, Verweij CL. J Rheumatol. 1997; 24: 55 - 60

281. Mechanism of action of antimalarial drugs: inhibition of antigen processing and presentation. Fox RI, Kang HI. Lupus. 1993 Feb; 2 Suppl 1: S912

282. Autophagy inhibitors. Pasquier B. Cell Mol Life Sci. 2016 Mar; 73(5): 985-1001

283. Mechanisms of action of hydroxychloroquine and chloroquine: implications for rheumatology. Schrezenmeier E, Dörner T. Nat Rev Rheumatol. 2020 Mar; 16(3): 155-166.

284. Antimalarials. Koranda FC. J Am Acad Dermatol. 1981 Jun; 4(6): 650-55 